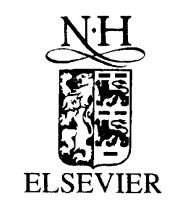

Lingua 113 (2003) 123-160

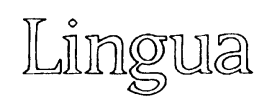

www.elsevier.com/locate/lingua

\title{
Motion events and the lexicon: a case study of Hindi ${ }^{\text {th }}$
}

\author{
Bhuvana Narasimhan* \\ Max Planck Institute for Psycholinguistics, PB 310, 6500 AH Nijmegen, The Netherlands
}

Received 27 January 2002; accepted 28 May 2002

\begin{abstract}
English, and a variety of Germanic languages, allow constructions such as The bottle floated into the cave, whereas languages such as Spanish, French, and Hindi are highly restricted in allowing manner of motion verbs to occur with path phrases. This typological observation has been accounted for in terms of the conflation of complex meaning in basic or derived verbs [Talmy, L., 1985. Lexicalization patterns: semantic structure in lexical forms. In: Shopen, T. (Ed.), Language Typology and Syntactic Description 3: Grammatical Categories and the Lexicon. Cambridge University Press, Cambridge, pp. 57-149; Levin, B., Rappaport-Hovav, M., 1995. Unaccusativity: At the Syntax-Lexical Semantics Interface. MIT Press, Cambridge, MA], or the presence of path "satellites" with special grammatical properties in the lexicon of languages such as English, which allow such phrasal combinations [cf. Talmy, L., 1985. Lexicalization patterns: semantic structure in lexical forms. In: Shopen, T. (Ed.), Language Typology and Syntactic Description 3: Grammatical Categories and the Lexicon. Cambridge University Press, Cambridge, pp. 57-149; Talmy, L., 1991. Path to realisation: via aspect and result. In: Proceedings of the Seventeenth Annual Meeting of the Berkeley Linguistics Society. Berkeley Linguistics Society, Berkeley, pp. 480-520]. I use data from Hindi to show that there is little empirical support for the claim that the constraint on the phrasal combination is correlated with differences in verb meaning or the presence of satellites in the lexicon of a language. However, proposals which eschew lexicalization accounts for more general aspectual constraints on the manner verb + path phrase combination in Spanish-type languages (Aske, J., 1989. Path Predicates in English and Spanish: A

is This is a revised version of aspects of my doctoral dissertation submitted to Boston University in 1998. I would like to thank Cathy O'Connor and Ray Jackendoff for extensive feedback on the ideas in this paper, as well as an anonymous referee, and the members of the Acquisition and Language and Cognition groups at the Max Planck Institute of Psycholinguistics for insightful comments during the writing of this article. I would also like to express my gratitude to Dan Slobin, Emile van der Zee, and the audiences at the Argument Structure conference of the Texas Linguistic Society (1999), the Linguistics Department, University of Illinois, Urbana-Champaign (March 2000), and the Language, Culture and Cognition Symposium, IIT, Delhi (December 2000) for their helpful comments on earlier versions of this material. I am solely responsible for the views presented here as well as any errors.

* Tel.: + 31-24-352-1231; fax: + 31-24-352-1213.

E-mail address: bhuvana@mpi.nl (B. Narasimhan).
\end{abstract}


Closer look. In: Proceedings of the Fifteenth Annual Meeting of the Berkeley Linguistics Society. Berkeley Linguistics Society, Berkeley, pp. 1-14) cannot account for the full range of data in Hindi either. On the basis of these facts, I argue that an empirically adequate account can be formulated in terms of a general mapping constraint, formulated in terms of whether the lexical requirements of the verb strictly or weakly constrain its syntactic privileges of occurrence. In Hindi, path phrases can combine with manner of motion verbs only to the degree that they are compatible with the semantic profile of the verb. Path phrases in English, on the other hand, can extend the verb's "semantic profile" subject to certain constraints. I suggest that path phrases are licensed in English by the semantic requirements of the "construction" in which they appear rather than by the selectional requirements of the verb (Fillmore, C., Kay, P., O'Connor, M.C., 1988, Regularity and idiomaticity in grammatical constructions. Language 64, 501-538; Jackendoff, 1990, Semantic Structures. MIT Press, Cambridge, MA; Goldberg, 1995, Constructions: A Construction Grammar Approach to Argument Structure. University of Chicago Press, Chicago and London).

(C) 2003 Elsevier Science B.V. All rights reserved.

Keywords: Event structure; Construction; Hindi; Linking; Lexicalization

\section{Introduction}

Debates on the nature of the syntax-semantics interface have noted the necessity of accounting for variation in the syntactic behaviour of semantically equivalent verbs crosslinguistically (Levin, 1998: 126). Yet most discussions of the issue are based on English data, and have been confined to the linking of the core NP arguments of the verb. A notable exception is to be found in Talmy $(1985,1991)$ who discusses a range of data from a number of languages, encompassing non-core elements such as path/locational expressions as well. In this paper, I discuss the phenomenon, originally pointed out by Talmy, whereby a verb encoding information about the cause/manner of motion in English (e.g. float) is able to combine with a path (into the cave) to convey directed manner/cause of motion within a single clause as in The bottle floated into the cave (1991: 488). Other languages (e.g. Spanish, French) cannot combine a manner of motion verb with a path/locational expression to conflate two events in a minimal clause, deeming ungrammatical the equivalent of The bottle floated into the cave (1985). Rather, only path of motion verbs can occur as the main verb of directed motion constructions; the causal/manner event must be expressed separately as an adjunct: La botella entró flotando a la cueva 'the bottle entered floating to the cave' (1991: 488). In this study, I examine Hindi constructions of the type discussed by Talmy (1985) in the domain of spontaneous motion. The scope of my investigation extends to any clausal construction in which a manner verb combines with a path/location-encoding (phrasal or lexical) element to imply directed manner of motion, e.g. The bottle floated in/ to the cave/ there. I term the clausal encoding of complex events "Complex Event Encoding" (henceforth CEE). ${ }^{1}$

\footnotetext{
${ }^{1}$ Constructions which involve complex event encoding include the cause/manner verb + path phrase construction The bottle floated into/out of the cave but not the path verb $\overline{\overline{+ \text { noun/prepositional phrase +adjunct }}}$ construction The bottle entered/emerged from the cave floating. Although both types of constructions encode directed motion as well as the causal/manner event, Complex Event Encoding constructions, as defined here encompass only the cause/manner verb + path phrase constructions which do not require an adjunct.
} 
How do we account for the differences in CEE across languages? Talmy advances two versions of what I term the "lexicalization hypothesis" which might provide an account of the phenomenon $(1985,1991)$. In his 1985 paper, Talmy accounts for the typological variation in terms of differences in the components of meaning encoded in morphemes of the same grammatical category (verb roots) in the two languages. English-type languages, which allow the directed manner of motion reading in a single clause (The bottle floated into the cave), have a range of verbs with both a simple (manner) meaning as well as a complex meaning (manner + motion)-socalled "lexicalization doublets" (1985: 64). Such polysemy is lacking in the lexical inventory of motion verbs in Spanish-type languages (1985: 64-66). That is, the verb lexicons in the two languages differ qualitatively, leading to differences in the clausal encoding of both the manner and the path of motion. A related claim is made in Levin and Rappaport-Hovav (1995), where the ability of agentive manner of motion verbs in English to occur in isolation, as well as with directed path phrases, is attributed to their association with two distinct lexical representations, a possibility presumably absent in languages which do not occur with path phrases.

In a subsequent paper however, Talmy focuses on accounting for the typological differences in terms of differences in the types of grammatical categories/relations which encode the path of motion meaning (1991). He distinguishes between Englishtype languages and Spanish-type languages on the basis of the types of grammatical morphemes in which the path (or "core schema") is lexicalized. In Spanish-type languages, termed "verb-framed" languages (1991: 486), the path (along with motion) is lexicalized in a set of open-class morphemes, viz. verb roots (e.g. entró 'enter' as in La botella entró flotando a la cueva 'the bottle entered the cave floating'). In English-type languages, termed "satellite-framed" languages, the path is lexicalized in a set of closed-class morphemes called "satellites" which include English verb particles [e.g. in (to + ), off], Russian verb prefixes, Atsugewi polysynthetic affixes, and Chinese verb complements, among others (1991: 486). I classify both types of explanation under the rubric "lexicalization hypothesis" since they rely on differences in the lexicons of the two languages to explain the typological differences.

In this paper, I show that Hindi patterns similarly with Spanish, French, etc. in excluding CEE. With the exception of certain restricted cases (to be discussed further in Section 6 of the paper), Hindi manner verbs cannot combine with path expressions to convey the manner of directed motion meaning. In this respect, Hindi displays the characteristics typical of verb-framed languages. However, while the Hindi data are compatible with Talmy's descriptive typology of verb-framed and satellite-framed languages (insofar as it is based on the syntactic co-occurrence privileges of manner of motion verbs), the mechanism proposed by Talmy $(1985,1991)$ to explain his observations - viz. the lexicalization patterns of a language (the semantics of the verb and/or the satellite) — cannot be extended to account for the restriction in Hindi on CEE, as broadly defined in this paper. Hindi and English do not differ in the lexicalization of complex meaning in the verb - the semantic properties of the motion verb lexicon in the two languages are similar in the relevant

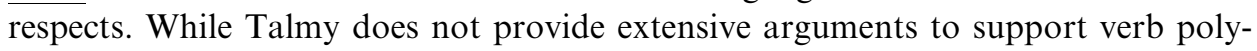
semy in English (vs. in verb-framed languages), such arguments are provided in Levin 
and Rappaport-Hovav (1995) who suggest that agentive manner of motion verbs in English are associated with a secondary (derived) directed motion sense as well. While their account is intuitively appealing, I show that these arguments do not receive strong empirical support. Another logical possibility (not explicitly addressed by Talmy) - that the extreme restriction on CEE is a consequence of sparsity in the number of manner of motion verbs in the Hindi lexicon - is also shown not to be the case. Hindi has a variety of verbs expressing motion in various manners/causes which could potentially be co-opted for use in CEE constructions of the type found in English.

Nor does the shift in focus in Talmy's 1991 paper-from using verb meaning as the basis for typological classification, to using the grammatically-defined locus of lexicalizing the path (the verb versus the satellite) — explain why Hindi differs from English in CEE, despite similarities in verb semantics. It is hypothetically possible that two languages could conflate similar semantic components (manner + motion) in the verb root, but might differ in whether the path component is lexicalized in a satellite or the verb. Since Talmy suggests that path-encoding satellites in English are restricted to verb particles, it is possible that the absence of verb particles in the Hindi lexicon deprives it of the mechanism which enables CEE in the language. However, the existence of path particles in the lexicon of a language is not a necessary condition for CEE. English allows path-encoding adpositional/adverbial phrases to combine with manner of motion verbs as well, even though they might lack the morphosyntactic properties peculiar to particles. Since path information is also encoded in adpositional/adverbial phrases in Hindi (in addition to verbs), it is not clear why these types of elements should fail to combine with manner (of motion) verbs in Hindi.

Clearly, the CEE differences between the two languages cannot be localized in differences in the properties of verbs or the existence of special grammatical morphemes in the lexicon. An "extralexical" constraint on their combination appears to be called for. Such a type of explanation has been proposed by Aske (1989) who observes that Spanish manner of motion verbs can occur with atelic path phrases but not telic ones, and proposes that aspectual factors constrain the combination of manner of motion verbs with path $\overline{\overline{\text { phrases. }^{2}}}$ I review Hindi data which provide support for the view that atelic path phrases are (relatively more) felicitous with manner of motion verbs than those which are telic. However, the formulation of the constraint on CEE using only aspectual notions wrongly predicts that a greater range of verbs in Hindi should occur with atelic path phrases than actually do so. Hence, although the notion of an extralexical constraint appears to be on the right track, it cannot be formulated in purely aspectual terms.

In order to account for the facts, I propose an alternative account formulated in terms of the role of verb semantics in constraining its syntactic privileges of occurrence

\footnotetext{
${ }^{2}$ In a modification of Aske's proposal, Slobin and Hoiting propose "movement across a boundary" rather than telicity as a more appropriate defining feature of events which resist CEE in verb-framed languages such as Japanese, Dutch Sign Language, Turkish, etc. (1994: 498); however, for the purposes of this paper, I will continue to frame the discussion in aspectual terms.
} 
across languages. I suggest that in Hindi, the selectional restrictions of the verb are strictly respected - the "semantic profile" of the verb determines the range of path phrases which can co-occur with it. ${ }^{3}$ In English, on the other hand, verb semantics may not always determine its surface syntactic distribution although it may constrain it. Path phrases which are not selected by the verb can nevertheless combine with the verb in "extralexical" phrasal constructions to add (directed motion) meaning. For instance, the verb squeeze does not entail a path of motion in isolation; and neither does the prepositional phrase through the crack require motion predicates (cf. She peered through the crack). Yet the two in combination are interpreted as implying change of location as in We squeezed through the crack (Aske, 1989: 9). The complex event semantics is lexicalized in neither the verb nor the path phrase alone, but is associated with the [Subject-V-Oblique] frame itself, viz. the "construction" (cf. Fillmore et al., 1988; Aske, 1989; Jackendoff, 1990; Goldberg, 1995). In Hindi, the equivalent frame cannot license the manner verb + path expression combination since it lacks the principle of correspondence which associates it with complex event semantics.

Summarizing, I propose that the data in Hindi are compatible with Talmy's descriptive typology, and displays "verb-framed characteristics" on the basis of its extreme restriction on the co-occurrence of manner verbs with path expressions to convey directed meaning. However, the basis for the difference between Hindi and English cannot be accounted for solely in terms of lexicalization: viz. the encoding of different types of meaning in the lexical entry of the verb, or in terms of the grammatical properties of the lexemes which encode path meaning. Rather, the difference lies in the role that phrase-level frames or "constructions" play in the grammar of the language. Further, a constructionally-based account is not mutually exclusive with a lexicalization account, but suggests an additional level of explanation for possible sources of variation in the mapping between syntax and lexical semantics across languages.

In the following section, I present data from Hindi, demonstrating its patterning with "verb-framed" languages in not allowing (what I term) complex event encoding (CEE). I then introduce Talmy's lexicalization hypothesis as originally formulated (1985) and show that it cannot account for differences in CEE between English and Hindi (Sections 3 and 4). In Section 5, I argue that Talmy's shift in focus to the role of satellites as the basis for typological classification also cannot explain the absence of CEE in Hindi. Aske's aspectual constraint is shown to be valid in Hindi for the range of data which he originally considers for Spanish (1989), however additional data suggest that lexical aspect may not be the only factor which plays a role in the crosslinguistic differences (Section 6). I conclude with an alternative proposal formulated in terms of the role of verb versus constructional semantics in determining the syntactic privileges of occurrence of the verb (Section 7 and 8).

\footnotetext{
3 See Jackendoff (1990: 53) for the proposal that selectional restrictions form part of the meaning (and argument structure) of the verb.
} 


\section{Spontaneous motion events: crosslinguistic data}

Hindi belongs to the Indo-European family of languages, and is historically derived from Sanskrit. It is spoken in a wide variety of states in Northern India including Uttar Pradesh, Madhya Pradesh, Bihar, Haryana, Rajasthan, Himachal Pradesh, and the Union Territory of Delhi (Shapiro, 1989). My informants are college-educated, native Hindi speakers who grew up in Hindi-speaking households and received their college education in India. They come from the following cities in Northern India: Jodhpur, Lucknow, Kanpur, Patna, and Delhi. ${ }^{4}$

In the following discussion, I define a semantically complex event as a non-stative event that is modified by a secondary non-stative event (generally a process) which bears a manner or means relationship to the primary event. English encodes complex events using two types of constructions. In the following example, the primary non-stative event is that of motion; the secondary modifying event describes the manner in which the motion occurs:

(1) Sydney hobbled to the door.

The manner of motion is described by the verb hobble, while the path of motion is described by the prepositional phrase to the door. The path of motion can also be expressed just with in which has been labelled as a "satellite" by Talmy (1985: 106):

(2) Sydney hobbled in.

The second way of encoding the complex event in English is to use an adjunct construction which allows the modifying event to be expressed as a participial adjunct-hobbling. The adjunct construction encodes the (deictic) path of motion with the verb come or a path-encoding verb such as enter/emerge, and specifies the path further with the Goal PP into the room:

(3) Sydney came hobbling into the room.

(4) The boy entered the room hobbling/emerged from the room hobbling. ${ }^{5}$

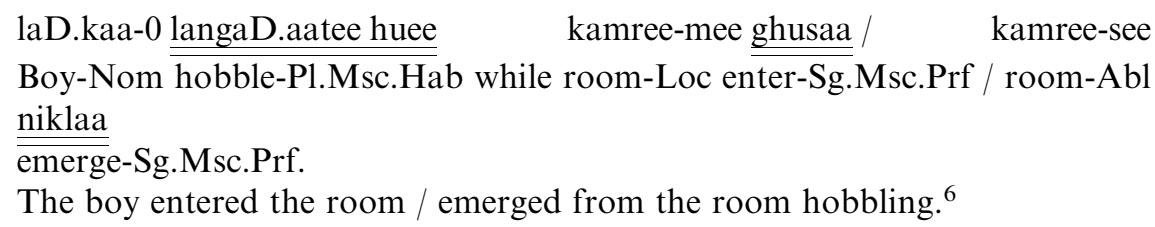

${ }^{4}$ Since bilingualism, and sometimes multilingualism is the norm among (educated) speakers in India, I could not control for interference from a variety of L2s including English, Telugu, Sanskrit, Persian, Urdu, and Panjabi.

5 As noted by an anonymous reviewer, path verbs such as enter in English occur in transitive constructions without a satellite (a verb particle such as in); for the purposes of this paper, we exclude from consideration, the transitive directed motion constructions involving path verbs in English.

${ }^{6}$ In the transliteration of the Hindi examples, the period after consonants indicates that the previous consonant is a flap rather than a stop; a period before nasal consonants indicates nasalization of the preceding vowel. 
CEE constructions include (1) and (2), but not (3)-(5) which use adjuncts to express the secondary event of manner/cause of motion.

Hindi is extremely restricted as to the range of verbs it allows in CEE constructions. A number of different verb-types are discussed below:

Non-directed translational motion verbs: Manner of motion verbs which are nondirected cannot occur with telic path phrases in Hindi: ${ }^{7,8}$

*laD.kaa-0 kamree-mee langaD.aayaa (OK on the locative reading)

*Boy-Nom room-Loc hobble-Sg.Msc.Prf.

The boy hobbled into the room.

The complex event can only be expressed using a construction with an adjunct-in this case, an imperfective participial form of the verb (e.g. langaD.aanaa 'hobble'), followed by huee ('while V-ing'); or a verb root affixed by a conjunctive particle kar ('by/after $\mathrm{V}$-ing'). ${ }^{9}$ The path of motion is expressed by the verb aanaa ('come') and the Goal specified further by the NP kamraa 'room' which is marked with Locative case -mee 'in':

laD.kaa-0 langaD.aatee $\quad$ huee / langaD.aakar
$\begin{aligned} & \text { Boy-Nom hamree-mee } \\ & \text { aayaa. }\end{aligned}$
come-

Sg.Msc.Prf.

The boy came into the room, hobbling

A range of verbs of manner of motion in Hindi exhibit a similar restriction against combining with path phrases:

(8) The boy crawled/strolled/ran/toddled to the store.

(9) *laD.kaa-0 dukaan-koo reengaa / Tahalaa /dauD.aa /Thumakaa.

*Boy-Nom store-Dat crawl- / stroll- / run- / toddle-Sg.Msc.Prf.

The boy crawled/strolled/ran/toddled to the store.

7 Glosses: Erg: Ergative; Nom: Nominative; Acc: Accusative; Dat: Dative; Gen: Genitive; Loc: Locative; Ins: Instrumental; NF: Non-finite verb; Pst: Past tense; Pres: Present tense; Fut: Future tense; $\overline{\overline{\overline{\text { Sgg}}}}$ : Singular;

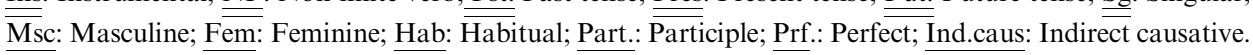

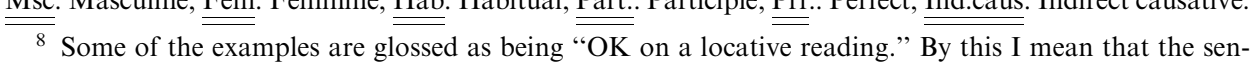
tence is well-formed if the adpositional phrase is interpreted as the location in which the event occurred rather than as the endpoint of directed motion.

9 There are differences in aspect associated with the use of one form versus the other. Hence, laD.kii khuudtee huee gayii ('The girl went, jumping') imparts a more process-like reading for the verb khuudnaa ('jump') implying many jumps, whereas laD.kii khuudkar gayii ('The girl went, with a jump/jumping') could mean a single jump which caused the translational motion, although the process interpretation is also possible with the - kar phrase (preferably with a reduplicated manner verb laD.kii khuud-khuudkar gayii 'The girl went, jump-jumping'). 
(10) laD.kaa-0 reengkar / Tahaltee huee/ dauD.kar/Thumakkar skool Boy-Nom crawl by / stroll-Pl.Msc.Hab. while/ run by / toddle by school-Dat gayaa.

go-Sg.Msc.Prf.

The boy went to school, crawling/strolling/running/toddling. ${ }^{10}$

"Self-contained" motion verbs: (Talmy, 1991: 489) English also allows path phrases with verbs which are not usually associated with translational motion. Rather, they imply change of position (lurch or flutter), movement on the vertical axis (bounce or jump) or movement around an axis (spin, gyrate):

(11) The ball bounced across the floor.

(12) She jumped out of the door. (single jump)

(13) She jumped across the desert. (single/many jumps)

(14) The man stumbled down the stairs.

(15) She lurched into the room.

(16) The bird fluttered to the ground.

(17) The top spun across the room.

Hindi does not allow the equivalents of such verbs to occur with path phrases:

(18) *bachchaa-0 darvaazee-koo uchhalaa / khuudaa *Child-Nom door-Dat spring (bounce)-Sg.Msc.Prf/ jump-Sg.Msc.Prf. The child sprang (bounced)/jumped to the door.

(19) *pakshii-0 zamiin-koo phaD.phaD.aayaa. *Bird-Nom ground-Dat flutter-Sg.Msc.Prf.

The bird fluttered to the ground.

(20) *kaagaz-0 pharsh-par sarsaraayee.

*Papers-Nom floor-Loc rustle-Pl.Msc.Prf.

The papers rustled on(to) the floor.

(21) *laTTuu-0 darvaazee-koo ghuumaa. *Top-Nom door-Dat spin-Sg.Msc.Prf.

The top spun to the door.

Verbs of noise-emission: English verbs of noise-emission can also co-occur with path phrases (22) even though they do not encode the notion of change of location (23):

(22) The train rattled out of the station.

(23) The train rattled but did not change location.

\footnotetext{
10 The Dative case-marker -koo on Goals is often elided in spoken Hindi.
} 
In Hindi, this is not possible:

*Treen-0 sTeeshan-mee see khaD.khaD.aayii *Train-Nom station-Loc Abl rattle-Sg.Fem.Prf. The train rattled out of the station.

Change-of-state verbs: Some change-of-state verbs which could be interpreted as resulting in a change of location of the Theme such as melt can also imply directed motion in English; such verbs are completely ill-formed with any type of directional phrase in Hindi:

(25) *chokleeT-0 Dibbee-mee see pighlii.

*Chocolate-Nom box-Loc Abl melt-Sg.Fem.Prf.

The chocolate melted out of the box.

(26) *ghar-0 zamiin-koo jalaa.

*House-Nom ground-Dat burn-Sg.Msc.Prf.

The house burned to the ground.

(27) *paudhee-0 kamree-mee ankurit huee.

*Plant-Nom room-Loc sprout be(come)-Pl.Msc.Prf.

The plants sprouted into the room. (OK in a locative sense)

Hindi thus differs markedly from English in the degree to which it allows manner of motion verbs to co-occur with (telic) path phrases. ${ }^{11}$ With the exception of a restricted number of cases, complex motion events can only be encoded in Hindi with adjunct constructions. In the next sections, I will investigate whether the differences noted in this section can be accounted for in terms of the lexicalization of meaning in verbs and "satellites" as proposed in Talmy $(1985,1991)$.

\section{Talmy's lexicalization hypothesis}

Talmy proposes to examine how the various semantic components comprising an event of motion are mapped onto the surface syntactic elements of a clause. He begins by identifying the elements of the basic schema underlying the motion event (1985: 61):

Figure: the object that is moving or located with respect to another object.

Ground: the reference-object with respect to which the Figure is moving or is located.

Path: the course followed or site occupied by the Figure object with respect to the

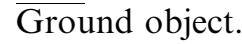

\footnotetext{
11 The case of atelic path expressions will be discussed in Section 6.
} 
Motion: the presence per se of motion or location in the event.

Cause/Manner: distinct external events that cause or modify the motion event.

Talmy proposes that the elements of this motion schema are lexicalized in typologically distinct ways.

In a motion-sentence pattern characteristic of one group of languages, the verb expresses at once both the fact of Motion and either its manner or its cause. A language of this type has a whole series of verbs in common use that express motion occurring in various manners or by various causes. (1985: 62)

In the second typological pattern for the expression of Motion, the verb root at once expresses both the fact of motion and the Path. (1985: 68)

Languages such as English lexicalize both manner and motion in the verb root, whereas languages such as Spanish do not lexicalize manner and motion in the verb root, but express the manner information in an adjunct. ${ }^{12}$ Talmy also proposes a third pattern in which the Figure is conflated in the verb root along with the "factof-Motion" in languages such as Atsugewi (1985: 72), however we shall not include this pattern in the present discussion.

These typologically contrasting patterns result in different syntactic privileges of occurrence of the same verb in English and Spanish. In the following example, the verb flotar 'float' in Spanish cannot be used as the syntactic head of the clause to describe the manner in which a change of location event occurs (29). In English however, float can also occur as the head of a clause with a path phrase, and is interpreted as the manner in which the bottle moves into the cave (28). The verb float can occur as a participial adjunct in both Spanish and English (examples 28 and 30 from Talmy, 1991: 488):

(28) The bottle floated into the cave.

(29) *La botella flotó a la cueva.

The bottle floated to the cave

(30) La botella entró flotando a la cueva.

The bottle moved-in floating to the cave.

Talmy suggests that a verb such as float represents distinct lexicalizations of meaning in English - it represents a lexicalization doublet (1985: 64). In its basic sense, it is stative and refers to "the buoyancy relation between an object and a medium" (p. 64):

(31) The craft floated/was afloat on a cushion of air.

$$
\underline{\underline{\text { float }}} \underline{\underline{1}}
$$

\footnotetext{
12 In using the term "lexical", Talmy explicitly refers to "single morphemes and, to a lesser extent, words (composed of root and derivational morphemes)" (1985: 58); at the level of meaning, Talmy uses the term "lexicalization" when a (set of) meaning component(s) is "in association with a morpheme, making up the whole of the morpheme's meaning" (1985: 59).
} 
In its second usage, it "includes the idea of motion together with that of buoyancy" (p.64):

(32) The craft floated into the hangar on a cushion of air.

$$
\underline{\underline{\text { float }}} \underline{\underline{2}}
$$

Talmy argues for the view that float represents two distinct lexicalizations on the basis of the existence of verbs which lexicalize just one or the other of the two senses (p. 65 ). Thus, the verb lie only has a stative sense, and cannot be used to express translational motion, whereas glide or drift express motion, but not stative location (p. 65):

(33) The pen lay on the plank/*down the incline.

(34) The canoe glided (*on that spot of the lake for an hour).

Talmy's account suggests that crosslinguistic differences arise from differences in the lexical resources available for encoding motion in verb-framed versus satellite-framed languages. There are two logical possibilities compatible with Talmy's analysis depending upon how the term "lexicalization patterns" is to be interpreted: (a) verbframed languages may not lexicalize manner of motion in verbs at all, thus accounting for the paucity of manner verb + path phrase combinations; (b) both satellite- and verb-framed languages lexicalize manner of motion; however manner of motion verbs in verb-framed languages have only a pure manner (of motion) sense, whereas satelliteframed languages are polysemous between a pure manner and a manner + directed motion reading. ${ }^{13}$ I discuss these in turn in the next sections.

\section{Lexicalization in the verb}

In Section 4.1, I begin by ruling out a logical possibility for the extreme restriction on the combination of manner of motion verbs with path expressions, viz. that there are lexical gaps in the Hindi lexicon such that manner of motion is rarely lexicalized in verbs at all. ${ }^{14}$ Having established that Hindi does indeed have a sizeable manner of motion verb lexicon, I go on demonstrate that these verbs lexicalize aspects of meaning which are highly similar to their English counterparts, and that verbs of manner of motion in English do not have an additional directed motion sense unavailable to their counterparts in Hindi. I use two lines of reasoning to support my contention that Hindi and English motion verb lexicons do not differ in syntactically

\footnotetext{
13 I use the phrase "directed motion" broadly, to encompass motion involving a "path" as defined in Talmy (1985).

14 Basque, for instance, appears to be a language in which the encoding of manner in the verb is exceedingly sparse, with many of the manner verbs in the language entering the lexicon as borrowings from Spanish; instead, the language relies on manner elaboration using native sound-symbolic verbs, adverbials, case-marked nominals, and participial forms (Ibarretxe-Antuñano, 2003)
} 
relevant semantic characteristics. In Section 4.2, I show that the additional sense of directed motion which manner of motion verbs appear to convey in English is available only when the verb co-occurs with a path phrase and never otherwise. In intransitive syntactic frames where a path phrase does not occur, Hindi and English verbs of manner of motion have highly similar lexical entailments with respect to the participants involved in the event, and the aspectual profile of the event described by the construction (cf. Dowty, 1979, 1991). This suggests that the additional directed motion meaning associated with the use of manner of motion verbs in English does not arise from the verb itself, but from its coocurrence with the path phrase.

However this argument, although necessary, is not in itself sufficient to assert that the manner of motion verbs in English do not have an additional sense of directed motion. It is possible that the additional meaning does not come from the path phrase, but from the verb, which when used in its secondary sense of directed motion always co-occurs with a path phrase. We thus have to consider whether there is independent evidence that the manner of motion verbs in English are polysemous, and do indeed have an additional distinct directed motion sense not available to verbs of manner of motion in Hindi. Although Talmy (1985) asserts that there are two distinct senses associated with each agentive verb of manner of motion in English, he does not provide independent evidence for this assumption. For a discussion of such issues, I turn to the account of "variable behaviour" verbs in Levin and Rappaport-Hovav (1995) where the case for more than one lexical semantic representation for agentive manner of motion verbs receives detailed treatment. In Section 4.3, I show that the arguments adduced in favour of an additional derived sense for agentive manner of motion verbs by Levin and RappaportHovav (1995) are empirically weak, and do not support the hypothesis that the verbs in English are (systematically) polysemous, and hence different from their counterparts in Hindi.

\subsection{Lexicalization patterns in Hindi}

Slobin (2000) notes that the lexicon of a satellite-framed language not only has a greater number of lexical items encoding manner of motion, but also encodes a greater variety of manner distinctions. Hence in the limiting case, the restricted use of manner verb + path phrase combinations in a language might be directly attributed to a near-absence of manner verbs of any kind in the motion verb lexicon. I show that this factor cannot be the source of restricted manner of directed motion constructions in Hindi.

The motion verb lexicon in Hindi consists of path verbs as well as a number of manner of motion verbs which could potentially combine with path expressions to convey the meaning of directed motion. Even a preliminary survey of motion verbs in Hindi and English, as in Table 1, suffices to show that Hindi has a sizable class of manner-of-motion verbs. If we translate 40 different English manner-of-motion verb roots into Hindi, then 25 of these have corresponding simple verbs in Hindi, the remaining being translated with paraphrases or complex predicates (not shown in Table 1). 
Table 1

Manner components in Hindi and English verbs of motion ${ }^{\mathrm{a}}$

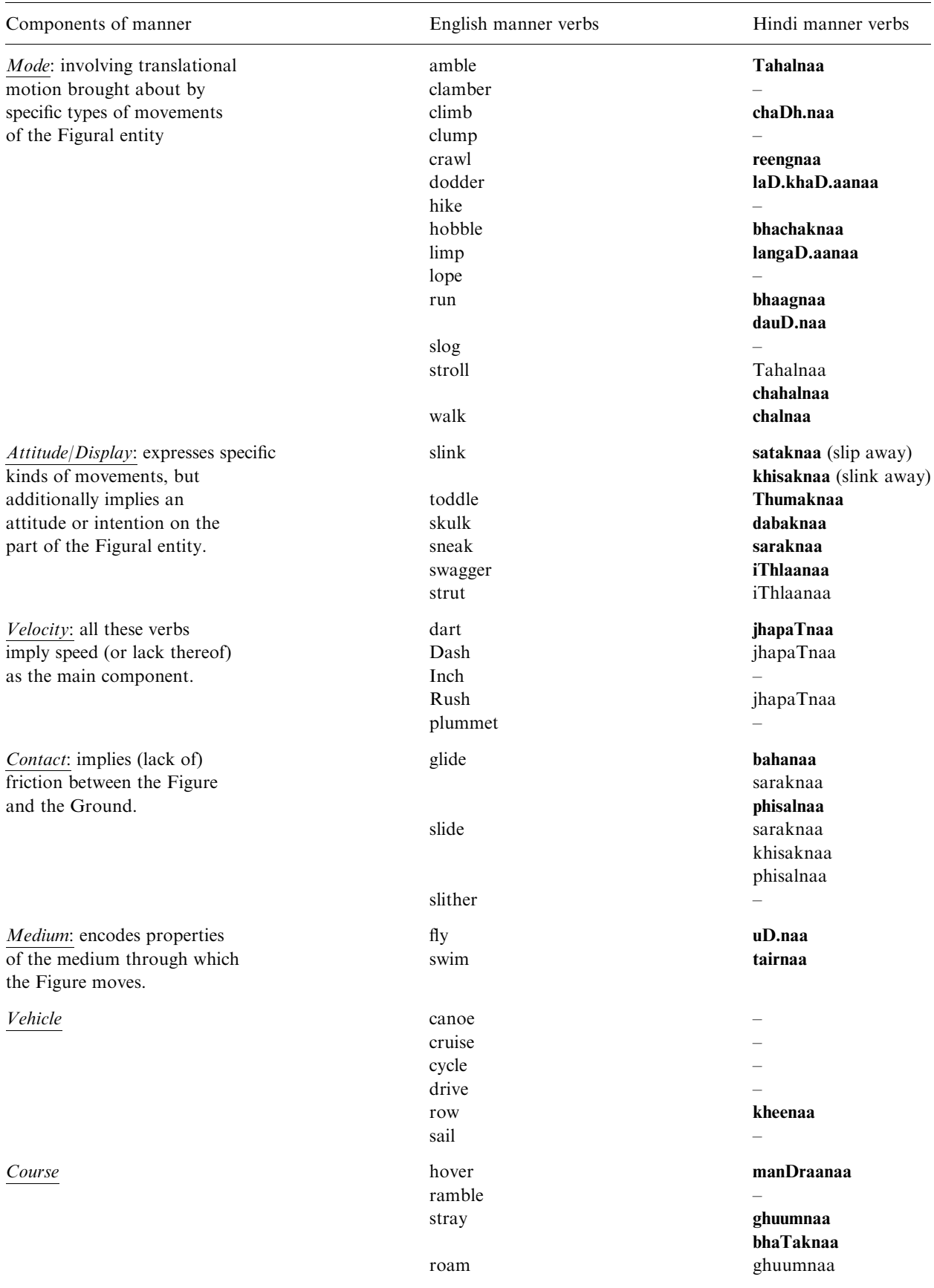

a First-mentions of Hindi verbs are given in boldface; subsequent repetitions are left unbolded. 
A class of 25 verbs can hardly be called minimal, and a larger-scale survey can only turn up more. If we examine the path verb lexicon for verbs which encode features which Talmy uses to illustrate the Spanish-style typological patterning, we find that Hindi lexicalizes even fewer path features in verbs than English does (Table 2).

This could be because, in addition to using path-encoding motion verbs, Hindi also uses the strategy of encoding deixis in main verbs such come or go (cf. Choi and Bowerman, 1991: 88 for a similar strategy in Korean spontaneous motion expressions) with adpositional/adverbial phrases to further specify the path (paas jaanaa 'near go' for approach), or encodes the path using complex predicates (paar karnaa

Table 2

Path components in Hindi and English verbs of motion ${ }^{\mathrm{a}}$

\begin{tabular}{|c|c|c|}
\hline Path & English verbs & Hindi verbs \\
\hline $\begin{array}{l}\text { Complex endpoint: } \\
\text { encodes features of } \\
\text { the endpoint, e.g. } \\
\text { whether it is an } \\
\text { enclosure }\end{array}$ & enter & ghusnaa \\
\hline $\begin{array}{l}\text { Complex source-point: } \\
\text { encodes features of the } \\
\text { source point }\end{array}$ & $\begin{array}{l}\text { emerge } \\
\text { issue }\end{array}$ & $\begin{array}{l}\text { nikalnaa } \\
\text { nikalnaa }\end{array}$ \\
\hline Simple endpoint & $\begin{array}{l}\text { reach } \\
\text { arrive }\end{array}$ & $\begin{array}{l}\text { pahu.nchnaa } \\
\text { pahu.nchnaa }\end{array}$ \\
\hline Simple potential endpoint & $\begin{array}{l}\text { approach } \\
\text { near } \\
\text { advance }\end{array}$ & $\begin{array}{l}- \\
\text { ba.Dhnaa } \\
\text { ba.Dhnaa }\end{array}$ \\
\hline Simple source-point & $\begin{array}{l}\text { leave } \\
\text { depart } \\
\text { recede }\end{array}$ & $\begin{array}{l}\text { chhooD.naa } \\
\text { chhooD.naa } \\
-\end{array}$ \\
\hline Midpoint & pass & guzarnaa \\
\hline Direction & $\begin{array}{l}\text { climb } \\
\text { ascend } \\
\text { rise } \\
\text { descend } \\
\text { fall } \\
\text { drop } \\
\text { circle } \\
\text { revolve }\end{array}$ & $\begin{array}{l}\text { chaDh.naa } \\
\text { chaDh.naa } \\
\text { uThnaa (posture) } \\
\text { utarnaa } \\
\text { girnaa } \\
\text { girnaa } \\
\text { ghuumnaa } \\
\text { ghuumnaa }\end{array}$ \\
\hline Deixis & $\begin{array}{l}\text { come } \\
\text { go }\end{array}$ & $\begin{array}{l}\text { aanaa } \\
\text { jaanaa }\end{array}$ \\
\hline Spatial features of the path & $\begin{array}{l}\text { cross } \\
\text { pierce }\end{array}$ & $\begin{array}{l}\text { kaaTnaa } \\
\text { ghusnaa }\end{array}$ \\
\hline
\end{tabular}

a First-mentions of Hindi verbs are given in boldface; subsequent repetitions are left unbolded 
Table 3

Partial inventory of motion verbs in English and Hindi

\begin{tabular}{lll}
\hline & Hindi & English \\
\hline Path + motion verbs & 14 & 24 \\
Manner + motion verbs & 25 & 40
\end{tabular}

'cross do'). Table 3 shows the relative numbers of path versus manner verbs in the two languages (focusing only on commonly used verbs in both languages).

Motion verbs in English fall into a range of subclasses based on the particular type of manner information they encode (Ikegami, 1969; Miller and Johnson-Laird, 1976). As the preliminary survey in Table 1 shows, Hindi lexicalizes a similar range of manner subcomponents, although not as extensively as English does. ${ }^{15}$ All the components that we distinguished in English are represented by simple verb roots in Hindi as well, although the finer distinctions are not as well represented. For instance, although the manner component labelled attitude is represented by simple verb roots, the distinction between strut and swagger is not lexicalized in Hindi. Many of the meanings lexicalized in the verb root in English are expressed by paraphrases in Hindi (only those meanings which can be translated with monomorphemic verb roots are shown in the table). Thus, plummet does not have a direct translational equivalent in Hindi, hence would be paraphrased by using an adverb in conjunction with a verb-verb compound (siidhee gir jaanaa 'straight/directly fall go'). The adverb specifies the precipitousness of the fall, while the use of the verbverb compound specifies the suddenness of the event (although gir jaanaa 'fall go' could also be paraphrased with the simple verb girnaa 'fall'). Similarly, the verb canoe is translated as 'go in a canoe' (Doongii-mee jaanaa 'canoe-Loc go'). Slither is paraphrased using a participial form of the verb phisal 'slip/slither' followed by huee 'while' and the path verb baDh.naa 'advance': phisaltee huee aagee baDh.naa 'slipping while forward advance'. ${ }^{16}$

Summarizing, even though there are fewer manner-of-motion verbs in Hindi compared to English, their number is not inconsiderable, and their semantic distribution in the manner domain (i.e. the number of different subcomponents of manner which these verbs encode) is comparable to that of the English manner-of-

\footnotetext{
${ }^{15}$ A list of intransitive motion verbs was constructed using Roget's International Thesaurus (Chapman, 1992) and Chambers English Dictionary (Schwartz et al., 1988), from which a smaller number was selected and grouped on the basis of Ikegami (1969), Miller and Johnson-Laird (1976), and Levin (1993). I then constructed Table 1 by comparing the translations of intransitive motion verbs in the two languages using McGregor's Hindi-English Dictionary (1993) and Bulcke's Angreezii-Hindi Shabdkoosh 'EnglishHindi Dictionary' (1995).

16 While Table 1 shows a range of manner components (of motion) lexicalized in both languages, it does not provide information about meaning components which might be lexicalized in Hindi, but not in English. Hence the diversity of manner of motion verbs in the Hindi verb lexicon might actually be underestimated in Table 1.
} 
motion verb lexicon. ${ }^{17}$ The highly restricted occurrence of CEE constructions in Hindi cannot hence be traced to a paucity of verbs with the requisite semantic properties, as has been argued for Spanish (Aske, 1989).

\subsection{Similar verb semantics in contexts without a path phrase}

While Hindi and English verbs of manner of motion appear to encode a similar range of meaning components, it is possible that the Hindi verbs differ from their English translational equivalents in subtler lexical semantic features which may be responsible for differences in the syntactic behaviour of the translational equivalents of the "same" verb across languages. If manner of motion verbs in English are inherently polysemous, with additional semantic features not encoded by their counterparts in Hindi, such differences may show up when the semantics of the verbs in the two languages are compared in similar syntactic contexts, viz. intransitive constructions without a path phrase. In this section, I provide evidence that in intransitive constructions without a path phrase, Hindi manner of motion verbs lexicalize the same salient aspects of meaning as do their counterparts in English (which can occur with path phrases). ${ }^{18}$

I use the entailments of the verbs as a measure of similarity, as well as their behaviour in standard aspectual diagnostics. ${ }^{19}$ On this basis, it can be demonstrated that equivalent verbs in the two languages have highly convergent semantics, yet diverge in their syntactic distribution. Furthermore, when two verbs do diverge in some aspect of meaning (e.g. animacy in the case of a verb like tairnaa 'swim'

17 A comparable picture emerges when we look at Spanish. Slobin (1996) conducts a survey of 60 stories elicited to describe a wordless, picture storybook (Frog, Where are you?, Mayer, 1969) in Spanish and in English. He finds that the number of manner of motion verbs is greater in English (47) than in Spanish (27) (Slobin, 1996:198), but suggests that ". . .both types of languages - verb-framed and satellite-framed-have constructions in which locative phrases can be used with verbs of motion to indicate landmarks" (1996: 214).

$18 \mathrm{CEE}$ as defined in this paper, refers to the combination of (manner) verbs with any expression which can be interpreted as specifying the path (and goal) of motion. If these path-encoding expressions are assumed to be adjuncts, their occurrence is less likely to be influenced by the lexical semantics of the verb than than if they are complements or even, as Talmy (1985) suggests, a type of element which forms a verb complex together with the verb root. However, it is difficult to decide a priori whether these expressions are adjuncts, arguments, or something in between. Indeed, Carrier and Randall (1992) argue in some detail that result phrases occur in complement positions (as sister to the verb). They show that the long distance extraction of result phrases is more felicitous than that of (what they consider to be) adjuncts such as depictive secondary predicates, at least in English. Given the possibility that at least some of the range of path expressions I consider in this paper are verbal complements, and that the distribution of adjuncts is not always independent of the influence of verb semantics, it is desirable that we establish similarity in verb semantics in Hindi and English, before going on to consider in more detail, the syntactic and semantic properties of the path-encoding expressions themselves (Section 5).

19 As Levin and Rappaport-Hovav (1995: 16) and Pesetsky (1995: 13) discuss, what qualifies as a "salient" aspect of meaning (read, able to influence syntactic mapping) is, a priori, not easily defined. An even more fine-grained semantic analysis might reveal dimensions of meaning lexicalized by verbs in English which are not encoded by verbs in Hindi, and which might influence syntactic complementation behaviour. Pending such an analysis, I shall assume that sharing a similar pattern of entailments and aspectual profile is a sufficient measure of similarity of those aspects of verbal meaning which are likely to influence the ability of a verb to co-occur with a path phrase. 
below), it can be shown that this semantic feature does not influence the verb's syntactic distribution. I shall demonstrate my case with the verbs langaD.aanaa 'hobble', Thumaknaa 'toddle', bahanaa 'drift', and tairnaa 'swim'.

The verb hobble in English does not entail movement in any particular direction in the absence of a directional phrase: Richard hobbled to and fro. However, it does entail displacement, i.e. an indefinite change of location - * Richard hobbled but stayed in the same place. Aspectually, the verb denotes a process: Richard hobbled for hours/*in an hour. The verb is also agentive: *The doll was hobbling. It can occur with both telic and

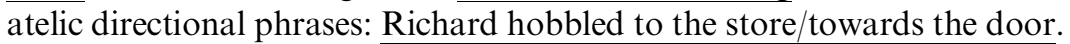

The verb langaD.aanaa 'hobble' in Hindi shows the same range of behaviour as the English verb hobble (except of course for its inability to cooccur with telic directional phrases). It specifies a particular manner of motion-specifically, it implies the same kind of gait as does the English verb hobble, and implies an animate agent. Like the verb hobble in English, it does specify indefinite change of location $(35,36)$. It is also an activity (37) and is agentive (and volitional) (38). It can occur only with atelic directional phrases $(39,40)$, although judgements on the example in (40) vary, eliciting grudging acceptance at the most:

(35) ??raamuu-0 langaD.aayaa leekin eek hii jagah-par Tikaa

??Raamuu-Nom hobble-Sg.Msc.Prf but one only place-Loc remain-Sg.Msc.Prf. rahaa.

stay-Sg.Msc.Prf.

??Raamuu hobbled but stayed in one place.

(OK if "one place" is interpreted as a large area within which the activity occurs)

(36) raamuu-0 idhar-udhar langaD.aayaa.

Raamuu-Nom here-there hobble-Sg.Msc.Prf.

Raamuu hobbled here and there.

(37) raamuu-0 saaree din langaD.aayaa /*eek ghanTee-mee langaD.aayaa. Raamuu-Nom all day hobble-Sg.Msc.Prf/*one hour-Loc hobble-Sg.Msc.Prf. Raamuu hobbled all day/*in an hour.

(38) laD.kii-0 jaanbuujhkar langaD.aa rahii thii.

Girl-Nom deliberately hobble stay-Sg.Fem.Prf. be-Sg.Fem.Pst.

The girl was hobbling deliberately.

(39) *raamuu-0 dukaan-koo langaD.aayaa

*Raamuu-Nom store-Dat hobble-Sg.Msc.Prf.

Raamuu hobbled to the store.

(40) ?raamuu-0 darvaazee-kii taraf langaD.aayaa.

?Raamuu-Nom door-Gen direction hobble-Sg.Msc.Prf.

Raamuu hobbled towards the door.

Other verbs of manner of motion include Thumaknaa 'toddle' and bahanaa 'drift'. Thumaknaa is agentive and encodes a manner of motion which encompasses the semantic range of the English verbs mince and toddle (for simplicity I have used toddle to gloss the examples in 41-52). The verb bahanaa is non-agentive and can be 
translated by glide, drift or flow (examples 53-64). I have used drift/glide to gloss the Hindi examples since, with non-liquid entities as the referent of surface subject nominal in the examples below (the "Figure" in Talmy's terms), the flow sense of bahanaa is not relevant. Both Thumaknaa and bahanaa show the same range of behaviour as their English counterparts, excepting their incompatibility with telic directional phrases $(49-50,61-62)$. They are similar with respect to participant roles; Thumaknaa and toddle imply animate (volitional) agents (47-48), while bahanaa and glide/drift allow non-agentive participants (59-60). They specify an indefinite change of location (41-44, 53-56), are activities (45-46, 57-58) and are relatively acceptable with atelic directional phrases (51-52, 63-64):

(41) Freddie toddled here and there.

(42) raamuu-0 idhar-udhar Thumakaa.

Raamuu-Nom here-there toddle-Sg.Msc.Prf.

Raamuu toddled here and there.

(43) *The child toddled but stayed in the same place.

(44) ?raamuu-0 Thumakaa leekin eek hii jagah-par Tikaa

?Raamuu-Nom toddle-Sg.Msc.Prf but one only place-Loc remain-Sg.Msc.Prf. rahaa.

stay-Sg.Msc.Prf.

?Raamuu toddled but stayed in one place.

(45) The child toddled for hours/*in an hour.

(46) raamuu-0 ghanTo.n tak Thumakaa /*eek ghanTee-mee Thumakaa.

Raamuu-Nom hours for toddle-Sg.Msc.Prf/ *one hour-Loc toddle-

Sg.Msc.Prf.

Raamuu toddled for hours / *in an hour.

(47) The girl/*the log was toddling deliberately.

(48) laD.kii-0 / *lakD.ii-0 jaanbuujhkar Thumak rahii

thii.

Girl-Nom/*log-Nom deliberately toddle stay-Sg.Fem.Prf. be-Sg.Fem.Pst.

The girl / *the log was toddling deliberately.

(49) Gus toddled to the store.

(50) ???raamuu-0 dukaan-koo Thumakaa

???Raamuu-Nom store-Dat toddle-Sg.Msc.Prf.

Raamuu toddled to the store.

(51) Agatha toddled towards the door.

(52) ?raamuu-0 darvaazee-kii taraf Thumakaa. ?Raamuu-Nom door-Gen direction toddle-Sg.Msc.Prf.

Raamuu toddled towards the door.

(53) The log drifted/glided here and there. 
(54) lakD.ii-0 idhar-udhar bahii.

Log-Nom here-there drift-Sg.Fem.Prf.

The log drifted here and there.

(55) *The log drifted/glided in the same place.

(56) ??lakD.ii-0 bahii leekin eek hii jagah-par Tikii

??Log-Nom drift-Sg.Fem.Prf. but one only place-Loc remain-Sg.Fem.Prf. rahii.

stay-Sg.Fem.Prf.

??The log drifted but stayed in one place.

(57) The log drifted/glided for hours/*in an hour.

(58) lakD.ii-0 ghanTo.n tak bahii /*eek ghanTee-mee bahii.

Log-Nom hours for drift-Sg.Fem.Prf./ *one hour-Loc drift-Sg.Fem.Prf.

The log drifted for hours/*in an hour.

(59) *The log was drifting/gliding vigorously.

(60) *lakD.ii-0 prabaltaa-see bah rahii thii.

*Log-Nom vigor-Inst. drift stay-Sg.Fem.Prf. be-Sg.Fem.Pst.

*The log was drifting vigorously.

(61) The boat drifted/glided to the shore.

(62) *naukaa-0 us kinaaree bahii

*Boat-Nom that shore-Dat drift-Sg.Fem.Prf.

The boat drifted to that shore.

(63) The boat drifted/glided towards the shore.

(64) ?naukaa-0 kinaaree-kii taraf bahii.

?Boat-Nom shore-Gen direction drift-Sg.Fem.Prf.

The boat drifted towards the shore.

The verb tairnaa has a wider semantic range than the English swim (for some speakers). It can apply to any object moving through water by propelling itself, e.g. with a motor in a motorboat (71-72). Thus, any agentive entity can "swim"; it does not have to be animate; hence, when used with a non-animate (agentive) participant, the verb tairnaa does not necessarily imply the movement of the hands and legs in order to cause motion through water (all speakers do not agree about this, and the question mark in front of naukaa 'boat' in examples $(72,76)$ below comes from one speaker's dislike of the inanimate, non-agentive sense of tairnaa 'swim'). However, when used with an animate agent, it does, like English, imply movement of the limbs in water. If this particular difference in meaning were responsible for the ability of the verb to take a telic path phrase, we would expect that the verb tairnaa in Hindi might be able to take a telic path phrase in either one of its senses. However, as we see in (74), a path phrase is inadmissible with the verb tairnaa whether or not it takes an animate participant. Furthermore, as we saw in example (39), the verb langaD.aanaa, which unlike the verb swim, is unambiguously agentive and requires an animate participant, cannot appear with a telic path phrase either. This suggests that 
animacy is not relevant to differences between Hindi and English in path phrase selection (or the lack thereof) with verbs of motion. In other respects, viz. implying indefinite change of location (65-68), durative activity (69-70), and relative felicity with atelic directional phrases (75-76), tairnaa patterns with swim:

(65) The girl swam here and there.

(66) laD.kii-0 idhar-udhar tairii.

Girl-Nom here-there swim-Sg.Fem.Prf.

The girl swam here and there.

(67) *The girl swam but stayed in the same place.

(68) *laD.kii-0 tairii leekin eek hii jagah-par Tikii

*Girl-Nom swam-Sg.Fem.Prf but one only place-Loc remain-Sg.Fem.Prf. rahii. stay-Sg.Fem.Prf.

*The girl swam but stayed in one place.

(69) The girl swam for hours / *in an hour.

(70) laD.kii-0 ?ghanTo.n tak tairii / *eek ghanTee-mee tairii.

Girl-Nom ?hours for swim-Sg.Fem.Prf/ * one hour-Loc swim-Sg.Fem.Prf. The girl swam for hours/*in an hour.

(71) The girl/*the log was swimming.

(72) laD.kii-0/?naukaa-0 tair rahii thii.

Girl-Nom /? boat-Nom swam stay-Sg.Fem.Prf. be-Sg.Fem.Pst.

The girl /? the boat was "swimming".

(73) The girl $/ *$ the boat swam to the shore.

(74) *naukaa-0/*laD.kii-0 us kinaaree tairii.

*Boat-Nom / *Girl-Nom that shore-Dat swim-Sg.Fem.Prf.

*The boat / the girl swam to the shore.

(75) The girl/*the boat swam towards the shore.

(76) laD.kii-0 / ?naukaa-0 kinaaree-kii taraf tairii.

Girl-Nom / ?boat-Nom shore-Gen direction swim-Sg.Fem.Prf.

The girl / *the boat swam towards the shore.

Other manner of motion verbs in Hindi pattern similarly to their counterparts in English, viz. they are durative, and entail both translational motion and manner of motion. They also entail participants which are similar to those entailed by their translational equivalents in English (Table 4).

We thus see that verbs which display differences in syntactic behaviour nevertheless pattern together in encoding very similar aspects of meaning in Hindi and English. However, similarity in meaning in Hindi and English verbs of motion in intransitive constructions (without a path phrase), does not preclude an additional, directed motion meaning associated with manner of motion verbs in English which shows up only in other syntactic contexts. We turn to this issue in the next section. 
Table 4

Properties of some manner of motion verbs in Hindi and English

\begin{tabular}{llllll}
\hline Verb & Durative & Telic & Manner & Motion & Participant \\
\hline Tahalnaa & Yes & No & Mode & Yes & Anim.agent \\
stroll & Yes & No & Mode & Yes & Anim.agent \\
uD.naa & Yes & No & Medium & Yes & Theme/anim.agent \\
fly & Yes & No & Medium & Yes & Theme/anim.agent \\
bhaTaknaa & Yes & No & Course & Yes & Anim.agent \\
wander & Yes & No & Course & Yes & Anim.agent \\
iThlaanaa & Yes & No & Display & Yes & Anim.agent \\
swagger & Yes & No & Display & Yes & Anim.agent \\
khisaknaa & No & Yes (?) & Display & Yes & Anim.agent \\
sneak & No & Yes (?) & Display & Yes & Anim.agent \\
jhapaTnaa & No & Yes & Velocity & Yes & Anim.agent \\
dart & No & Yes & Velocity & Yes & Anim.agent \\
phisalnaa & Yes (?) & No (?) & Contact & Yes & Theme/agent \\
slide & Yes & No & Contact & Yes & Theme/agent \\
khenaa & Yes & No & Vehicle & Yes & Anim.agent \\
row & Yes & No & Vehicle & Yes & Anim.agent \\
\hline
\end{tabular}

\subsection{No verb polysemy}

Determining whether a verb has more than one sense is a difficult and thorny issue, given the sensitivity of verb semantics to "coercion" in different syntactic contexts (Pustejovsky, 1995). Nevertheless, diagnostics have been proposed which function as probes with respect to the lexical semantic structure of verbs (Goldberg, 1995; Levin and Rappaport-Hovav, 1995). One way in which verb meaning can be probed is to test their entailments in a gerundival context. Goldberg (1995) suggests that the basic meaning of the verb can be gauged from its entailments when used in following frame (p. 43):

$$
\text { No __ ing occurred. }
$$

Thus, if we say "no hitting occurred", we associate it with a two participant interpretation (involving motion and contact), whereas with "no sneezing ocurred" we expect a one-participant interpretation (p. 43). If a verb is polysemous, then it should potentially be ambiguous between a number of different meanings.

If a verb root is inherently associated with two senses, or if a lexical rule (zero-) derived a new verb with a directed motion meaning, then we might expect the verb swim in the frame no swimming occurred or the verb sneeze in the frame no sneezing occurred to be interpreted in different ways. However, this is not the case. In this syntactic frame, swim implies only the activity of a participant moving in a characteristic way in water, without implying directionality; and sneeze only implies a one-participant activity, rather than a two-participant interaction as might be expected if its meaning included causative change of location (as in She sneezed the handkerchief off the table). 
The lack of a secondary directed motion sense can be established for a range of agentive manner of motion verbs including hobble, sashay, rustle, fly, run, dart, among others. Contrast this with the entailments of a verb such as rent in the frame no renting occurred where there are two possible interpretations - no paying of money to someone in exchange for temporary possession of goods occurred or no receipt of money from someone in exchange for temporary possession of goods occurred-depending on which aspect of the complex structure of the verb one focusses on. If agentive manner of motion verbs such as hobble or swim had a complex interpretation as well, I argue that they should also be ambiguous in a similar way.

These arguments however, do not preclude the possibility that the additional directed motion sense of English manner of motion verbs appears only in the presence of a (directional) path phrase. That is, verbs of manner of motion in English have a secondary (derived) directed motion sense which requires an obligatory path phrase; hence the secondary sense is always manifested in the presence of a path phrase, and never without it. Thus, Levin and Rappaport-Hovav (henceforth L\&RH) suggest that agentive manner of motion verbs have basic and derived meanings; the derived sense is the output of a lexical rule which takes as its input, the unergative verb of agentive manner of motion (e.g. hobble), and yields an unaccusative verb with a directed motion sense which always takes a path phrase (1995). ${ }^{20}$ Since Hindi verbs of manner of motion do exhibit the agentive nondirected sense, but not the directed motion sense, the inability of Hindi manner of motion verbs to co-occur with path phrases presumably arises from the absence of a lexical rule which derives the directed motion verb for this class of verbs. Such a line of reasoning rests on the assumption that the verbs of manner of motion in English do indeed have two distinct lexical senses, and L\&RH provide a number of types of evidence in support of this assumption. However, as argued in Narasimhan et al. (1996) and summarized in part below, the evidence provided in L\&RH does not provide adequate empirical support for a secondary derived sense for English manner of motion verbs.

One line of reasoning provided by L\&RH (pp. 186-187) has to do with the fact that swim in the fake reflexive resultative pattern (77) is unergative but is unaccusative in the unaccusative resultative pattern in (78). However, when followed by a change of state rather than a change of location result phrase, it is ill-formed in the unaccusative resultative construction in (79):

(77) Don't expect to swim yourself sober.

(78) They slowly swam apart.

(79) *Don’t expect to swim sober.

According to L\&RH, agentive manner of motion verbs are ill-formed in the unaccusative resultative pattern with a change of state result phrase because they are the output of a lexical rule that adds a directional phrase to the argument structure

${ }^{20} \mathrm{~L} \& \mathrm{RH}$ assume that it is the non-directed motion sense that is more basic although they do not provide reasons for this assumption. 
of the verb. Hence the agentive manner of motion verb can only appear with a result phrase denoting a location, and not a state.

However, an alternative explanation for the ill-formedness of (79) could be traced to the fact that the range of result phrases which can occur in resultatives is restricted to canonical (and sometimes idiomatically fixed) endpoints of the event described by the verb (Wechsler, 1996):

(80) He wiped the table clean/spotless/*wet/*streaky.

(81) I shot him dead/??wounded.

The infelicity of (79) is a consequence of the fact that motion verbs designate a "locative goal" as a canonical result rather than a change of state (1996: 2). These examples suggest that verbs of change of state do not undergo a lexical shift; rather, the interpretations we get emerge from general semantic constraints imposed by the selectional restrictions of the verb on the result phrase.

A second argument in favour of a lexical rule is provided in aspectual terms (L\&RH: 201). The sentence in (82) implies a single jump, whereas (83) strongly implies a series of jumps (Jackendoff, 1990: 224). L\&RH suggest that this has to do with the unaccusative classification of jump in (82), as opposed to its unergative classification in (83):

(82) Willy jumped into Harriet's arms.

(83) Willy jumped his way into Harriet's arms.

The unaccusative use, they suggest, "must never involve an iteration of events" (p.201) as opposed to Jackendoff (1990: 224$)$ who claims only that (82) "can consist of a single jump" (emphasis mine). The following sentences with agentive manner of motion verbs are all counterexamples to L\&RH's stronger claim. They can all be interpreted as involving a series of events (as well as a single event):

(84) Willy hopped across the room.

(several hops)

(85) Harriet wriggled towards the door. (many wriggles)

(86) The drunk stumbled down the road. (several stumbles)

(87) The child jumped up the stairs.

(many jumps)

Again, the differences in interpretation have to do with the semantico-pragmatic constraints associated with the verb and the directional phrase rather than differences in the verb's argument structure.

Further evidence is provided in the form of causativization patterns in English. L\&RH suggest that agentive manner of motion verbs in isolation do not causativize, whereas they are well-formed in the presence of a directional phrase (p. 188):

(88) ??The general marched the soldiers

(89) The general marched the soldiers to their tents. 
(90) *We ran the mouse.

(91) We ran the mouse through the maze.

According to L\&RH, the causativization operation is possible only because the external argument of the unergative verb is no longer present (as a consequence of the lexical shift which "demotes" the external argument to internal argument status), which thus allows an external argument to be "added" when the verb is causativized (see also Pinker, 1989). Since the unaccusative variant is associated with the directed motion meaning, the directional path phrase is also required.

Since it is rule-governed, this process is predicted to be relatively productive (L\&RH, p. 188). If all agentive manner of motion verbs can undergo a lexical shift in the presence of a directional phrase, they should fit the input conditions for causativization. However, the constructions below are not felicitous:

(92) ??John swam/ran/danced the children apart.

(93) *She jumped/leapt the cat clear of the oncoming vehicle.

(94) *The general trudged/ambled the tired soldiers to their tents.

(95) *We sashayed/swaggered the models along the catwalk.

Such counterexamples suggest that the causativized constructions in (89) and (91) are not products of a rule-governed process but are highly restricted cases constrained by specific semantico-pragmatic factors (cf. Rosen, 1996).

Of the diagnostics that Levin and Rappaport-Hovav use-viz. the fake reflexive, the (aspectual interpretation of) the directed motion construction, and the causative construction, only the latter construction occurs with manner of motion verbs in Hindi. If causativization does indeed provide support for a derived unaccusative meaning for manner of motion verbs, then verbs of (agentive) manner of motion in Hindi, which, like their English counterparts, can also be causativized, must also have an unaccusative variant which forms the input to the causativization process. In fact, causativization in Hindi is more liberal than it is in English. Hence, while John toddled the puppet towards the door or Bill swam the boy towards the house is ungrammatical in English, even with a directional phrase, their counterparts in Hindi are perfectly grammatical even without a directional phrase: ${ }^{21}$

(96) laD.kee-nee kaTputlii-koo Thumakaayaa.

Boy-Erg puppet-Acc toddle-Caus-Sg.Msc.Perf.

*The boy toddled the puppet.

(97) Us-nee laD.ke-koo tairaayaa.

He-Erg boy-Acc swim-Caus-Sg.Msc.Perf.

*He swam the boy.

(98) Siitaa-0 guD.iyaa-koo nacaaeegii.

Siitaa-Nom doll-Acc dance-Caus-3.Sg.Fem.Fut.

*Siitaa will dance the doll. 
If causativization does involve a shift in the classification of the verb from unergative to unaccusative, then Hindi agentive manner of motion verbs should be similar to their English counterparts in their ability to take directional phrases as well. Their inability to do so suggests that such a meaning shift is not implicated in the ability of a verb to take directional phrases in Hindi.

One counterargument which could be made is that causativization in Hindi is not the same as in English, and hence does not involve a similar meaning shift. The causative construction in Hindi (a) involves the addition of causative morphology, whereas in English it is lexical, (b) does not require a directional phrase with manner of motion verbs when causativized, whereas in English it is obligatory (Levin and Rappaport-Hovav, 1995: 198), and (c) operates on a wider range of verbs than English including those verbs with which English would use periphrastic causative constructions. Hence, for the sake of argument, it might be asserted that causativization in Hindi does not involve a shift of the unergative verb to unaccusative status (even though causativization in both languages appears to be similar in adding an external causer argument, while the single argument of the intransitive verb is assigned the status of an internal "causee" argument). If this were true, languages which have causativization properties similar to that of Hindi should show a similar restriction with respect to directional phrases. However, this appears not to be the case. The causativization data cited in L\&RH from Modern Hebrew (pp. 113-114), suggest that in Hebrew, as in Hindi, causativization of agentive manner of motion verbs involves a morphological process, does not require a directional phrase, and extends to a wider range of internally-caused verbs than in English. Yet Modern

21 While the possibility of causativization suggests that intransitive manner of motion verbs in Hindi should have the requisite lexical structure for the licensing of directional phrases, an additional question has to do with whether the manner of motion verbs, when causativized, behave in the same way as intransitive manner of motion verbs with respect to their (in)ability to take directional phrases. Causativized motion verbs such as Thumakaa 'toddle-Caus' and tairaa 'swim-Caus' are judged infelicitous with telic phrases, although with atelic directional phrases, we find that the judgements are more variable, depending on the directional term used (replacing the directional term taraf 'direction' in (a) below for the more infrequently used word oor which also means 'direction' renders the sentence infelicitous for some informants, see Narasimhan, 1998: 23-24). In some cases, even telic directional phrases can cooccur with motion verbs such as sarakaa 'slide' and phisalaa 'slip' whose semantics do not specify a particular movement pattern on the part of the Theme/Figure:

(a) laD.kee-nee kaTputlii-koo darvaazee-kii taraf Thumakaayaa.

Boy-Erg puppet-Acc door-Gen direction toddle-Caus-Sg.Msc.Prf.

*The boy toddled the puppet towards the door.

(b) mai.n-nee kalam-koo Dibbee-mee sarakaayaa / ?phisalaayaa.

I-Erg pen-Acc box-Loc slide-Caus-Sg.Msc.Prf./ slip-Caus-Sg.Msc.Prf

I slid/slipped the pen into the box.

For a discussion of how the interaction of verb semantics and telicity of directional phrases might create a gradient of verb-construction mappings in both transitive caused motion and intransitive motion constructions, see Narasimhan (1998: 23-24, 174-177). 
Hebrew differs from Hindi in allowing (directional) path phrases to co-occur with manner of motion verbs (p. 183).

We thus have two kinds of counterexamples to a meaning shift explanation for the differences between Hindi and English manner of motion verbs in directed motion constructions. The fake reflexive, aspectual interpretation, and causativization facts in English suggest that manner of motion verbs in English are not associated with two distinct lexical semantic representations. Hence, the ability of path phrases to co-occur with manner of motion verbs in English cannot be attributed to an additional derived verb meaning. This conclusion is buttressed by a second type of evidence, viz. the ability of manner of motion verbs to causativize in Hindi, which suggests that even if a verb has the ability to undergo a meaning shift, it may nevertheless show extreme restriction in the licensing of a path phrase.

Thus, while L\&RH provide a detailed and thorough description of "variable behaviour" verbs in light of the unaccusativity hypothesis, the lexical rule mechanism they propose to explain the properties of agentive manner of motion verbs is not wellsupported empirically, suggesting that verb polysemy does not underlie the syntactic flexibility of manner of motion verbs in English in directed motion constructions involving path phrases.

\section{Properties of satellites}

Perhaps a better explanation for the facts might be found in Talmy's 1991 study where the focus shifts away from the semantics of the verb root, and to the grammatical locus for the lexicalization of the path component. Talmy proposes that the two-way classification of languages made in the 1985 study can also be motivated in terms of the locus of encoding of the path element - the "core schema" of the motion event" (1991: 483). In verb-framed languages, the path is encoded (together with any ground elements) in the verb root (the bottle entered the cave floating), while in satellite-framed languages, the path is encoded in "satellites' to the verb (the bottle floated into the cave). Such a criterion for typological classification is compatible with the possibility that two languages can have similar manner-verb lexicons, yet differ in how the path is lexicalized (in the verb vs. the satellite).

The term "satellite" itself is defined as "the grammatical category of any constituent other than a nominal complement that is in a sister relation to the verb root" (1991: 486). ${ }^{22}$ However, the range of grammatical categories that occur in a "sister relation to the verb root" is wide, and includes free words or bound affixes such as English verb particles, German separable and inseparable verb prefixes, Latin or Russian verb prefixes, Chinese verb complements, Lahu non-head "versatile verbs", Caddo incorporated nouns, and Atsugewi polysynthetic affixes around the verb root (1991: 486). Talmy suggests that since satellites "belong to particular recognizable grammatical

\footnotetext{
22 Satellite-framed languages include most Indo-European excluding Romance languages, Finno-Ugric, Chinese, Ojibwa and Walpiri (Talmy, 1991: 486). Verb-framed languages include Romance, Semitic, Japanese, Polynesian, Tamil, most Mayan, Nez Perce, Caddo, and most Bantu (1991: 486).
} 
categories. . it seems better to consider the satellite role not as a grammatical category in its own right but as a new kind of grammatical relation" (1985: 102).

Let us begin with Talmy's criteria for identifying satellites (verb particles) in English (1985: 105). He suggests that in many languages, the satellite and the preposition are clearly distinguished by occupying different positions in the sentences. Thus, in Russian. Classical Greek, and Latin, satellites are found pre-verbally. The following example is from Russian (p. 105):

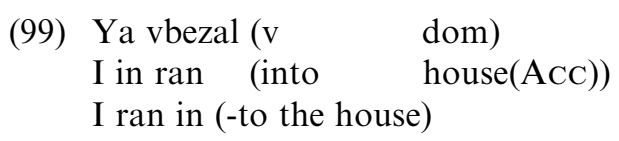

In English, however, the satellites are found post-verbally, and just adjacent to the prepositional phrase (100). In some cases, they merge (103) and Talmy refers to them as "satellite-prepositions" (p. 106):
(100) I went in to him. satellite and a preposition
(101) I followed him in. satellite
(102) I went to him. preposition
(103) I went past him. satellite-preposition

Satellites exhibit properties which differ from those of adpositions (and by implication, adverbs), according to Talmy (1985: 105). A satellite can occur intransitively [John ran by versus John ran to *(the house)], and satellites often have different senses than their corresponding prepositions (I went to the store versus I came to) (1985: 105).

It is not always easy to uniquely identify satellites, despite the diagnostics that Talmy suggests (for a discussion of satellite-like elements including verb particles, adverbs, and prepositional phrases, see Bolinger, 1971; Fraser, 1976; Brugmann, 1981; Dixon, 1982; Lindner, 1982; Kayne, 1985; Bas, 1989; Hoekstra and Mulder, 1990; Neeleman, 1994; den Dikken, 1995; Jackendoff, 1997; Sawyer, 1999, among many others). For instance, elements such as together, apart, and forth (1985: 105) are classified as satellites on the basis of the fact that these elements do not take NP complements (in the way that prepositions do, e.g. She walked from the store vs. *She walked from). However, it is not clear how they differ from adverbials such as here or there which also do not take NP complements (but which are not considered to be clear-cut cases of satellites; 1985: 149, fn. 141). Further, although into, to, and towards are used to exemplify the satellite-framed pattern in various examples (1985: 65-67), they are not satellites by the NP-omission diagnostic, since they cannot occur on their own in motion constructions such as *She walked to (although to behaves like a satellite in its non-motion sense, as in She came to; in the motion sense it is classified as a preposition; 1985: 105).

To the extent that Hindi lacks verb particles, Talmy's claim that paths are not encoded in satellites in verb-framed languages is valid. However, for the purposes of explaining differences in the encoding of complex events as I have defined it (Section 
Table 5

The non-verbal encoding of path in Hindia

\begin{tabular}{|c|c|}
\hline $\begin{array}{l}\text { (-kee/-see) baahar } \\
\text { (-kee) andar, -mee } \\
\text {-see } \\
\text { (-kee) uupar } \\
\text {-par } \\
\text { (-kee) niichee } \\
\text { (-kee) aagee, (-kee) saamnee } \\
\text { (-kee) piichhee } \\
\text { (-mee) see, (-kee) aarpaar } \\
\text { (-kee) paas } \\
\text { (-kee/-see) alag } \\
\text { (-see) duur } \\
\text { (-kee) samaanaantar, saathh-saathh } \\
\text { (-kee) chaaroo.n oor } \\
\text { (-kee) saathh } \\
\text { (-kii) oor, (-kii) taraf, -kii dishaa mee, } \\
\text {-koo, tak } \\
\text {-see hookar, (-kee) raaste see, (-kee) saamnee see } \\
\text {-kee paar } \\
\text { yahaa.n, idhar } \\
\text { vahaa.n, udhar }\end{array}$ & $\begin{array}{l}\text { outside (of }+ \text { ) } \\
\text { in (side) }(\text { of }+) \text {, in } \\
\text { from }+ \\
\text { up, above }(+) \text {, on (top of }+ \text { ) } \\
\text { on }+ \text {, at }+ \\
\text { underneath }(+) \text {, below }(+) \text {, under } \\
\text { in front }(\text { of }+ \text { ), facing }+ \\
\text { behind }(+ \text { ) } \\
\text { out of }+ \text {, (right) through }(+) \\
\text { near }(+), \text { next (to }+ \text { ) } \\
\text { away (from }+ \text { ) } \\
(\text { far) away } \\
\text { along }(+) \\
\text { around }(+) \\
\text { together }(\text { with }+ \text { ) } \\
\text { towards }+ \text { to }+ \\
\text { via }+, \text { by }(+), \text { past }(+) \\
\text { across }+ \\
\text { here } \\
\text { there }\end{array}$ \\
\hline
\end{tabular}

${ }^{a}$ The majority of the forms given in this table can have a path-reading only with telic motion verbs; otherwise they have locational readings.

1), the existence of satellites cannot be a necessary condition for CEE. In addition to particles, path-encoding adpositional and adverbial phrases can also be used with manner of motion verbs to encode complex events in English, even though they are not satellites or satellite-prepositions (She walked there today, They flew from Rome, I hobbled towards the door, He crawled in our direction). Hence, we cannot conclude that a systematic gap in the Hindi lexicon (the absence of verb particles) is the factor responsible for the absence of CEE, since Hindi also has (compound) adpositional/adverbial phrases which could potentially combine with manner of motion verbs in CEE constructions as do their English counterparts. A partial list (based on Aske, 1989: 4-5 and Bulcke, 1995) is provided (Table 5). ${ }^{23}$

These expressions convey a path/goal with path verbs (such as ghusnaa 'enter' or jaanaa 'go'), however they cannot be used in a similar way with manner of motion verbs.

One could argue over whether Hindi adpositional phrases are syntactically equivalent to their English counterparts. For instance, although prepositions head their own phrases in English, paths are encoded with postpositional case-marked noun phrases (cf. Mohanan, 1990). However, to the extent that the Hindi case

23 The postpositions -mee 'on', -see 'from', and -par 'on' are simple postpositions which encode paths; whereas the compound postpositions include combinations of a variety of adverbial forms (which can occur on their own as well) with nouns affixed with the Genitive postposition -kee 'of', e.g. ghar-kee saamnee 'in front of the house'. 
postpositions pattern similarly to English prepositions in not being able to omit NPs, and occur in a similar range of positions as English PPs (e.g. as locational complements of directional verbs such as put, or as oblique arguments of transfer verbs such as give), our argument that Hindi has similar resources for CEE as English does is valid.

Note that a semantic constraint on the lexicalization of path in non-verbal elements cannot be posited in the case of Hindi. For instance, Dini and Di Tomaso (1997) suggest that the preposition a cannot combine with most manner of motion verbs in Italian (to imply directed motion) since it lexicalizes a static locative meaning only (contra Zingarelli (1995) and Serianni (1988), whom they cite as proposing that the preposition a has both static and locative senses). While it is not easy to locate the source of polysemous readings (e.g. how much of the directed motion sense in the bottle floated under the bridge comes from float versus under? cf. Carter, 1988), there are clear cases in Hindi, where only a directional sense is lexicalized in the adposition.

Adpositions such as the Dative -koo 'to/towards', Ablative -see 'from', and the complex postposition -mee see 'in from' are infelicitous in contexts which imply only a static location:

(104) Victoria will sit in the store/*out from the store.

(105) raadhaa-0 dukaan-mee /*dukaan-mee see baiTheegii.

Raadhaa-Nom store-Loc /*store-Loc Abl sit-3.Sg.Fem.Fut.

Raadhaa will sit in the store/*out from the store.

(106) John slept in the room/*to the room.

(107) raam-0 kamree-mee /*kamree-koo soyaa.

Raam-Nom room-Loc /* room-Dat sleep-Sg.Msc.Prf.

Raam slept in the room/*to the room.

The Hindi postpositions are also as infelicitous with verbs of "putting" as are the English directional prepositions. "Put" verbs imply causing an entity to reach a certain location (typically by moving), hence the endpoint is semantically a Goal of the motion of the Theme. However, since the verb lexicalizes the endpoint of the motion rather than the path of motion itself, it tends to take a location rather than a path complement. Hence, only phrases which encode a location can occur with such verbs; path-encoding phrases with prepositions such as to or from cannot occur as complements of these verbs (Levin, 1993: 111). Such verbs do entail motion of the Theme as seen in the infelicity of the following:

*Harry arranged/put/placed/stashed the books on the shelf but they did not change location.

If -see 'from', -mee see 'in from', and -koo 'to/towards' only specify a location, we would expect that they would be felicitous with verbs requiring a locational phrase. However, this is not the case: 
(109) Harriet put the book on the table/*to the table.

(110) ritu-nee kitaab-koo meez-par /*meez-koo rakhaa. Ritu-Erg book-Acc table-Loc / *table-Dat put-Sg.Msc.Prf. Ritu put the book on the table / *to the table.

(111) Bertie arranged the clothes on the ground $/ *$ to the ground.

(112) vivek-nee kapD.oo.n-koo pharsh-par / *pharsh-koo sajaayaa. Vivek-Erg clothes-Acc floor-Loc / *floor-Dat arranged-Sg.Msc.Prf. Vivek arranged the clothes on the floor $/ *$ to the floor.

(113) John spread the blanket on the table/*out of the box.

(114) bhaanuu-nee kambal-koo palang-par/*Dibbee-mee see bichhaayaa. Bhaanuu-Erg blanket-Acc cot-Loc /*box-Loc Abl spread-Sg.Msc.Prf. Bhaanuu spread the blanket on the cot $/ *$ out of the box.

(115) Cheryl stood the books on the shelf $/ *$ to the shelf $/ *$ from the shelf.

(cf. Levin, 1993: 112)

(116) bhaanuu-nee kitaabee.n-0 taak-par /*taak-koo /*taak-see khaD.ii

Bhaanuu-Erg books-Nom shelf-Loc $/ *$ shelf-Dat $/ *$ shelf-Abl stand-Fem.Prf kii.n. do-Pl.Fem.Prf.

Bhaanuu stood the book on the shelf $/ *$ to the shelf $/ *$ from the shelf.

This suggests that there is no semantic difference between "path" prepositional phrases in English (with from, to, and out of), and their case-postpositional counterparts in Hindi.

Thus, accounting for differences between Hindi and English in CEE in terms of the properties of the lexical resources of the language - verbs with complex meanings or satellites with special grammatical/semantic properties - does not receive much empirical support. Talmy's alternative suggestion, viz. an appeal to "a new kind of grammatical relation" between verbs and particular grammatical categories (particles, prepositions, light verbs etc.) could provide a more satisfactory account. However, how one is to interpret "grammatical relation" is a difficult question. In the following section, I consider whether the crosslinguistic variation can be accounted for in terms of language-specific aspectual constraints on the relationship between the verb and the path phrase, and conclude that a solely aspectual account does not account for the full range of data. I suggest that greater explanatory value lies in interpreting Talmy's "grammatical relation" as a more general mapping constraint on how path phrases are licensed in the syntax with a range of manner/cause verbs.

\section{An aspectual explanation}

One account which also eschews a strictly lexicalization-type account is found in Aske (1989) who draws similar conclusions for Spanish to those I have discussed for Hindi. Aske notes that even though the equivalent of John floated out of the room 
must be translated as Juan salió de la habitación flotando 'John exited the room floating' in Spanish, the language also has plenty of examples of manner-plus motion verbs in combination with path phrases such as La botella flotó por el canal 'the bottle floated along/about the canal' (1989: 3). Aske suggests that the restricted distribution of path phrases in Spanish relative to English cannot be traced to a lexical gap in the language since "there seems to be a path adverbial for just about every English path 'satellite' which could perform its function" (p. 3).

Rather, he proposes that we must distinguish between two types of directional/ path phrases in English: atelic locative path phrases which modify the verb or predicate a location for the entire proposition, and telic path phrases which predicate an end state or "culmination point" resulting from a previous activity (pp. 6-7). Spanish has only the atelic type of path phrase, and can only add locations, not predicate a resulting end-state of an activity described by the verb:

La botella flotó hacia $/ *$ a la cueva.
The bottle floated towards /*to the cave.

Aske distinguishes between telic path phrases and those atelic path phrases which are "bounded". Telic path phrases such as a la cima 'to the top' imply a "culmination point", whereas atelic locative path phrases such as hasta la cima 'upto the top' are modificational and not imply a culmination point, even though they indicate a bounded region in space (1989: 6-7). The atelic nature of bounded locative path phrases, when combined with activity manner-plus-motion verbs, is evident in their incompatibility with telic durational adverbials caminó hasta la cima (?* en dos horas) 'walked upto the top (?*in two hours)' (1989: 7, his example 24a).

Aske's observations are supported by data from Hindi as well; a manner verb is less infelicitous with an atelic path phrase than with a telic one (cf. Section 4.2):

laD.kaa-0 darvaazee kii taraf dauD.aa.

Boy-Nom door-Gen direction run-Sg.Msc.Prf.

The boy ran towards the door.

?laD.kaa-0 kamree-kii oor langaD.aayaa.

?Boy-Nom room-Gen direction hobble-Sg.Msc.Prf.

The boy hobbled towards the room.

(120) ?Dibbaa-0 yahaa.n-see vahaa.n tak phisalaa.

?Box-Nom here-Gen there till slip-Sg.Msc.Prf.

The box slipped from here till there.

Could Aske's proposal of a general constraint on the use of non-verbal path predicates in Spanish (to specify the endpoint of activity verbs) be extended to Hindi as well? Data from Hindi suggest otherwise. Whereas Aske notes that the felicity of the manner verb + path phrase combinations is influenced by verb semantics (1989: 3), he does not specifically address the following issue in his account: if the combination of non-verbal predicates with manner/activity verbs in Spanish (and presumably other verb-framed languages) is constrained only aspectually, then atelic path phrases should be compatible with a similar range of verbs in a verb-framed language as in a 
satellite-framed language. However, this prediction is not borne out in the case of verbs of "self-contained motion" (121-122), and verbs of noise-emission (123-124) in Hindi:

*saamp-0 darvaazee-kii taraf kulbulaayaa.

*Snake-Nom door-Gen direction wriggle-Sg.Msc.Prf.

The snake wriggled towards the door.

*kaagaz-0 darvaaze-kii oor phaD.phaD.aayaa.

*Paper-Nom door-Gen direction flutter-Sg.Msc.Prf.

The paper fluttered towards the door.

*kaagaz-0 meez-see sarsaraayee.

*Papers-Nom table-Abl rustle-Pl.Msc.Prf.

The papers rustled off the table.

*reelgaaD.ii-0 sTeeshan-mee see khaD.khaD.aayii.

*Train-Nom station-Loc Abl rattle-Sg.Fem.Prf.

The train rattled out of the station.

It appears then that the aspectual constraint must be modified to allow for interactions between verb semantics and path phrase semantics since the addition of any information which does not conform to the verb's specifications is ruled out in Hindi, not just the addition of an endpoint. As we saw in Section 4.2, manner of motion verbs (such as in example (40)) entail an indefinite change of location, but not an endpoint, and are hence compatible with atelic path phrases. However, the verbs in (121-124) do not imply motion at all, and do not combine with even atelic path phrases to convey translational motion. Thus, an optional (atelic) path phrase is compatible with a manner/activity verb only to the extent that it further specifies the change of location already implied by the verb in Hindi. The examples in (121124) are hence more adequately explained in terms of the role of verb semantics in constraining its syntactic privileges of occurrence in Hindi, rather than a constraint formulated in purely aspectual terms. We discuss this further in the next section.

\section{A crosslinguistic constraint on CEE: the role of verbs versus constructions}

The limitations of a purely aspectual restriction on the combination of manner of motion verbs with path phrases suggests that the crosslinguistic difference between Hindi and English in CEE is best formulated in terms of language-specificity in the mapping of path phrases in the syntax:

The occurrence of oblique paths in Hindi is strictly constrained by the semantics of the verbal head of the clause. English has in addition, the option of allowing path phrases to extend the verb's semantic profile.

Thus, manner of motion verbs in both English and Hindi have similar agentive, non-directed semantics; however, the additional directed motion sense associated 
with these verbs in English is contributed by a language-specific mapping rule which allows such verbs to co-occur with the $\mathrm{V}+$ Path Phrase construction. Such a move amounts to weakening the assumption that all syntax-semantics correspondences are universal and necessarily mediated by the lexical semantics properties of the verb alone (as formulated, for instance, in the Universal Theta Alignment Hypothesis (UTAH) (Baker, 1988)).

While the influence of verb semantics in constraining the syntactic distribution of path phrases might be the default option for both Hindi and English, the mechanism which allows English the option of extending verb semantics in non-standard ways remains to be specified. The precise characterization of such a mechanism is not within the scope of this paper, however I will briefly outline one possible solution to the problem which falls generally under the "constructional" approach (Fraser, 1976; Fillmore et al., 1988; Aske, 1989; Jackendoff, 1990; Goldberg, 1995). Construction-based accounts propose that pieces of syntactic structure bigger than a word might be associated with fixed (complex) meanings such as causative change of state or directed motion. One instance of a fixed pairing of meaning and phrasal form is the partially filled X's way construction, exemplified by talk one's way out of prison which has the meaning of getting out of a particular location or situation by talking. The general meaning of caused change of location cannot be attributed to the verb talk nor to the array of other verbs which can also occur in the verbal slot: talk/argue/sing/ smile one's way out of prison. Unless we want to posit that each of these verbs has an additional caused motion sense which only allows a fixed direct object (possessive pronoun way), we must assume that it is the phrasal form V-Poss.Pronoun.Way-PP itself which has the caused change of location meaning associated with it (Jackendoff, 1990; Goldberg, 1995). The X's way construction then is an instance where the semantics of the verb is extended by the semantics of the syntactic frame itself.

We can then extend the notion of constructional meaning to cases which are not associated with any fixed lexical items at all (e.g. X's way), viz. the syntactic template itself. The claim is that in such cases, a particular fixed meaning, such as manner/cause of directed motion, is lexicalized in neither the verb nor the path phrase (alone), but is associated with the [Subject-V-Oblique] frame as a whole (Goldberg, 1990: 160, Fig. 7.2). This fixed correspondence of complex meaning with an abstract syntactic template is the mechanism which licenses a manner-of-motion interpretation for even non-motion verbs such rattle or melt in combination with a path phrase.

Note however, that there are also restrictions on the productivity of this construction. ${ }^{24}$ It is not the case that English allows just any verb to randomly combine with a path phrase to imply directed motion:

\footnotetext{
${ }^{24}$ Levin and Rappaport-Hovav (1995: 206) assume that the constructional approach predicts that two language with the same construction should not differ in the range of verbs they allow in that construction. Hence, they take the fact that language languages differ in whether or not they allow agentive manner of motion verbs in the directed motion construction as evidence against the constructional approach. However, in the account proposed in this paper, the language-specific differences in the range of verbs allowed in the directed motion construction arise from the differences in the "constructional semantics" associated with the V+ Path Phrase template, an assumption which does not require the derivation of entire classes of verbs with complex meanings in some languages, but not others.
} 
While there are seemingly arbitrary lexical restrictions on the verbs which can appear in this construction, a general semantico-pragmatic constraint seems to be that only verbs which can be interpreted being "causally linked" to the event motion can occur in this construction (Croft, 1991: 160, as quoted in Goldberg, 1995: 61-62). Thus, verbs such as rustle or rattle do not themselves imply translational motion, yet they are produced as a result of the motion of the Figure. Verbs such as blow in the paper blew off the chair can be interpreted as causing the event of motion. However, verbs such as laugh do not fall in either category, hence are not felicitous in this construction. Goldberg (1995: 62) suggests that the cause/result relationship may not hold of other construction types, e.g. the X's way construction. An example of this would be:

(126) She sang/laughed/hiccupped her way to the store

Such examples suggest that the constraints on how verb semantics interacts with the meaning associated with the syntactic frames is not only language-specific, but also, within a language, construction-specific (Goldberg, 1995: 66).

In addition to restricting the range of verbs which can occur in the spontaneous directed motion construction, a constructional account must also account for the variety of path phrases which can occur with these verbs. For instance, we can account for the occurrence of both telic and atelic path phrases with manner/activity verbs in terms of "constructional underspecification/polysemy". The meaning associated with the frame in English might be underspecified with respect to whether the path has an endpoint or not, or polysemous between atelic or telic directed motion, allowing path phrases of either type to occur in the construction and determine the overall aspectual nature of the clause. In fact, as Goldberg points out, even expressions normally associated only with a locative meaning (e.g. within, inside) can receive goal interpretations when used in the [Subject-V-Oblique] frame, as in Sam squeezed the rubber ball inside the jar (1995: 158-159).

Accounting for the crosslinguistic differences in terms of a constructional mapping constraint rather than an aspectual constraint makes predictions with respect to semantic domains other than that of spontaneous motion. Aske (1989: 6) suggests that the restriction on telic non-verbal predication holds in Spanish in semantic domains other than motion. The telicity constraint also rules out the equivalent of change of state constructions such as Pat kicked the door open or She knocked the door down in Spanish. This is true of Hindi as well $(127,128)$, however the mapping constraint predicts that the extension of verbal semantics in any construction should be illicit, including those which do not involve telic path/result phrases at all. The constructions in $(129,130)$ involve semantic extensions of the verbs gurraanaa 'growl' and muskuraanaa 'smile' (cf. Levin and Rapoport, 1988) which do not involve telic non-verbal path phrases, yet they are still infelicitous in Hindi, as expected:

$$
\begin{aligned}
& \text { ??mai.n-nee darvaazee-koo band Dhakeelaa. } \\
& \text { ??I-Erg door-Acc shut push-Sg.Msc.Prf. } \\
& \text { I pushed the door shut. }
\end{aligned}
$$


(128) *mai.n-nee kuttoo.n-koo khaamoosh maaraa.

*I-Erg dogs-Acc silent beat-Sg.Msc.Prf.

I beat the dogs silent.

us-nee apnaa krodh-0 *gurraayaa/prakat kiyaa.

He-Erg self anger-Nom * growl-Sg.Msc.Prf. /express do-Sg.Msc.Prf.

He growled/expressed his annoyance.
us-nee mehmaanoo.n-kaa swaagat-0 *muskuraayaa/kiyaa
He-Erg guests-Gen welcome-Nom *smile-Sg.Msc.Prf./do-Sg.Msc.Prf.
He smiled/conveyed his welcome to his guests.

The variable role played by phonologically unspecified "argument structure constructions" (Goldberg, 1995) in the grammar of a language might hence account for the differences in CEE discussed at the beginning of this paper. While the type of verb-driven syntactic mapping assumed by most theories of grammar appears to be the default across languages, the constructional mechanism affords additional mapping possibilities in some languages, making possible the composition of complex event semantics in a single clause. ${ }^{25}$ In a language such as Hindi, the equivalent frame cannot license the complex interpretation since it lacks a similar correspondence with complex event semantics.

\section{Conclusion}

In this paper I examine the phenomenon termed "Complex Event Encoding", defined broadly as the clausal encoding of complex events. I present evidence that $\mathrm{CEE}$ - specifically the combination of a manner verb with a path/location-encoding element to imply directed manner of motion - is extremely restricted in Hindi relative to English. In this respect, Hindi displays the characteristics of verb-framed languages such as Spanish, rather than those of satellite-framed languages such as English. The aim of this paper however, is not to dispute Talmy's descriptive typology, but to examine the mechanism he proposes to underlie his empirical observations, viz. differences in patterns of lexicalization of meaning in verbs and satellites across languages. This account locates the source of crosslinguistic variation in the syntactic behaviour of (agentive) manner of motion verbs in the types of meaning encoded in lexical items.

An examination of the data suggests however that Hindi does not differ from English in the lexical resources required for CEE-its lexicon includes manner of motion verbs as well as path adpositions/adverbials whose semantic properties parallel those of their counterparts in English when they occur in equivalent syntactic environments. However, it is possible that English manner of motion verbs exhibit an additional directed motion sense only in combination with a path phrase, a syn-

\footnotetext{
25 As suggested by an anonymous reviewer, it is possible to replace verb-driven mapping by constructional mapping entirely, provided of course, that the consequences of such a move are empirically well-supported.
} 
tactic environment in which the Hindi verbs cannot occur. The arguments proposed in favour of this possibility however are shown to be empirically weak.

A logical alternative solution is to localize the crosslinguistic variation at the phrasal rather than the lexical level. Hence, lexical elements which are similar across languages might nevertheless be constrained in different ways in how they combine phrasally. Constraints on the combination of manner verbs with path phrases which are formulated in terms of aspectual factors such as telicity are too general and cannot account for the full range of data in Hindi. The mechanism proposed in place of the aspectual account makes use of the notion of "constructions" which receives independent motivation in the existence of partly compositional idioms in language which must be listed as a pairing of (phrasal) form and (complex) meaning in the lexicon (Fraser, 1976; Fillmore et al., 1988; Aske, 1989; Jackendoff, 1990; Goldberg, 1995).

Formulating the source of crosslinguistic variation in CEE in terms of a verbconstruction mapping constraint avoids the empirical problems faced by the lexicalization hypothesis since two languages can have equivalent ways of expressing path alone or cause/manner (of motion) alone, yet differ in whether their combination is licensed by a phrasal construction in their lexicon (a possibility excluded by Talmy's lexicalization hypothesis). It also provides an explanation for the non-occurrence of atelic path phrases with cause/manner (of motion) verbs in Hindi in terms of the selectional restrictions imposed by the verb. Whether or not a path phrase can occur with a manner verb in Hindi depends, not (only) on aspectual factors but also on the more general semantic profile of the verb, viz. what the verb entails with respect to translational motion along a path. While such an account provides a more empirically adequate framework for the facts, the exact nature of the compatibility constraints between path-phrase/verb semantics and constructional semantics within and across languages is a thorny problem which still remains to be worked out. Whether the differences between other verb-framed and satellite-framed languages in Talmy's typology can be explained in terms of lexical (word-level) meaning, construction-level semantics, or a hybrid model, requires further research.

\section{References}

Aske, J., 1989. Path Predicates in English and Spanish: A Closer Look. In: Proceedings of the Fifteenth Annual Meeting of the Berkeley Linguistics Society. Berkeley Linguistics Society, Berkeley, pp 1-14.

Bas, A., 1989. Verb-preposition constructions and small clauses in English. Journal of Linguistics 25, 277-290.

Baker, M.C., 1988. Incorporation: A Theory of Grammatical Function-Changing. University of Chicago Press, Chicago, IL.

Bolinger, D., 1971. The Phrasal Verb in English. Harvard University Press, Cambridge, MA.

Brugmann, C., 1981. The Story of Over. MA Thesis, University of California, Berkeley.

Bulcke, K., 1995. Angreezii-Hindi Shabdkoosh: An English-Hindi Dictionary, third ed. S. Chand \& Co., New Delhi.

Carrier, J., Randall, J.H., 1992. The argument structure and syntactic structure of resultatives. Linguistic Inquiry 23, 173-234.

Carter, R.J., 1988. On linking: papers by Richard Carter. In: Levin, B., Tenny, C. (Eds.), Lexicon Project Working Papers 25. Center for Cognitive Science, MIT, Cambridge, MA. 
Chapman, R.L., 1990. Roget's International Thesaurus. HarperCollins, New York, NY.

Choi, S., Bowerman, M., 1991. Learning to express motion events in English and Korean: the influence of language-specific lexicalization patterns. Cognition 41, 83-121.

Croft, W., 1991. Syntactic Categories and Grammatical Relations. University of Chicago Press, Chicago. den Dikken, M., 1995. Particles. Oxford University Press.

Dixon, R., 1982. The grammar of English phrasal verbs. Australian Journal of Linguistics 2, 149-247.

Dini, L., Di Tomaso, V., 1997. Linking Theory and Lexical Ambiguity: The Case of Italian Motion Verbs. Quaderni del Laboratorio di Linguistica 9. Scuola Normale Superiore, Pisa.

Dowty, D.A., 1979. Word Meaning and Montague Grammar. Kluwer Academic Publishers, Dordrecht.

Dowty, D.A., 1991. Thematic proto-rules and argument selection. Language 67, 547-619.

Fillmore, C., Kay, P., O’Connor, M.C., 1988. Regularity and idiomaticity in grammatical constructions. Language 64, 501-538.

Fraser, B., 1976. The Verb-Particle Combination in English. Academic Press, New York.

Goldberg, A.R., 1995. Constructions: A Construction Grammar Approach to Argument Structure. University of Chicago Press, Chicago and London.

Hoekstra, T., Mulder, R., 1990. Unergatives as copular verbs: locational and existential predication. The Linguistic Review 7, 1-79.

Ibarrretxe-Antunano, 2003. Motion events in Basque narratives. In: Strömqvist, S., Verhoeven, L. (Eds.), Relating Events in Narrative: Typological and Contextual Perspectives. Lawrence Erlbaum Associates, Mahwah, NJ.

Ikegami, Y., 1969. The Semological Structure of the English Verbs of Motion. Yale University, New Haven.

Jackendoff, R., 1990. Semantic Structures. MIT Press, Cambridge, MA.

Jackendoff, R., 1997. Twistin' the night away. Language 73, 534-559.

Kayne, R., 1985. Principles of particle constructions. In: Gueron, J., Obenauer, H.-G., Pollock, J.-Y. (Eds.), Grammatical Representation. Foris, Dordrecht, pp. 101-140.

Levin, B., 1993. English Verb Classes and Alternations: a Preliminary Investigation. University of Chicago Press, Chicago, IL.

Levin, B., 1998. Building verb meanings. In: Butt, M., Geuder, W. (Eds.), The Projection of Arguments: Lexical and Compositional Factors. CSLI Publications, Stanford, CA.

Levin, B., Rapoport, T., 1988. Lexical subordination. In: Papers from the Twenty Fourth Regional Meeting, Chicago Linguistic Society. University of Chicago, Chicago, IL, pp. 275-289.

Levin, B., Rappaport-Hovav, M., 1995. Unaccusativity: at the Syntax-Lexical Semantics Interface. MIT Press, Cambridge, MA.

Lindner, S., 1982. What goes up doesn't necessarily come down: the ins and outs of opposites. In: Tuife, K., Schneider, R., Chametsky, R. (Eds.). Papers from the 18th Regional Meeting of the Chicago Linguistic Society, pp. 305-323.

Mayer, M., 1969. Frog, Where Are You. Dial Press, New York.

McGregor, R.S., 1993. The Oxford Hindi-English Dictionary. Oxford University Press, New Delhi.

Miller, G.A., Johnson-Laird, P.N., 1976. Language and Perception. Belknap Press of Harvard University Press, Cambridge, MA.

Mohanan, T., 1990. Arguments in Hindi. Doctoral dissertation, Stanford University, Stanford, CA.

Narasimhan, B., 1998. Encoding Complex Events in Hindi and English. Unpublished doctoral dissertation, Boston University, Boston, MA.

Narasimhan, B., DiTomaso, V., Verspoor, K., 1996. Unaccusative or Unergative? Verbs of Manner of Motion. Quaderni del Laboratoria di Linguistica 10. Scuola Normale Superiore, Pisa.

Neeleman, A., 1994. Complex Predicates. Doctoral dissertation, Utrecht University, The Netherlands.

Pesetsky, D., 1995. Zero Syntax: Experiencers and Cascades. MIT Press, Cambridge, MA.

Pinker, S., 1989. Learnability and Cognition: The Acquisition of Argument Structure. MIT Press, Cambridge, MA.

Pustejovsky, J., 1995. The Generative Lexicon. MIT Press, Cambridge, MA.

Rosen, S.T., 1996. Events and verb classification. Linguistics 34, 191-223. 
Sawyer, J., 1999. Verb Adverb and Verb Particle Constructions: Their Syntax and Acquisition. Unpublished Doctoral dissertation, Boston University.

Schwartz, C., Davidson, G., Seaton, A., Tebbit, V. (Eds.), 1988. Chambers English Dictionary. Cambridge University Press, Cambridge.

Serianni, L., 1988. Grammatica Italiana. UTET, Torino.

Shapiro, M.C., 1989. A Primer of Modern Standard Hindi. Motilal Banarsidass, New Delhi.

Slobin, D.I., 2000. Verbalized events: a dynamic approach to linguistic relativity and determinism. In: Niemeier, S., Dirven, R. (Eds.). Evidence for Linguistic Relativity. Mouton de Gruyter, Berlin.

Slobin, D.I., 1996. Two ways to travel: verbs of motion in English and Spanish. In: Shibatani, M., Thompson, S.A. (Eds.), Grammatical Constructions: Their Form and Meaning. Clarendon Press, Oxford, pp. 195-221.

Slobin, D.I., Hoiting, N. 1994. Reference to movement in spoken and signed languages: typological considerations. In: Proceedings of the Twentieth Annual Meeting of the Berkeley Linguistics Society. Berkeley Linguistics Society, University of California, Berkeley, pp 487-505.

Talmy, L., 1985. Lexicalization patterns: semantic structure in lexical forms. In: Shopen, T. (Ed.), Language Typology and Syntactic Description 3: Grammatical Categories and the Lexicon. Cambridge University Press, Cambridge, pp. 57-149.

Talmy, L., 1991. Path to realisation: Via aspect and result. In: Proceedings of the Seventeenth Annual Meeting of the Berkeley Linguistics Society. Berkeley Linguistics Society, Berkeley, pp. 480-520.

Wechsler, S. 1996. Explaining Resultatives without Unaccusativity. Unpublished MS, University of Texas at Austin.

Zingarelli, N., 1995. Vocabolario della Lingua italiana. Zanichelli, Bologna. 